This item was submitted to Loughborough's Research Repository by the author.

Items in Figshare are protected by copyright, with all rights reserved, unless otherwise indicated.

\title{
Performance-based seismic design of steel structures accounting for fuzziness in their joint flexibility
}

\section{PLEASE CITE THE PUBLISHED VERSION}

https://doi.org/10.1016/j.soildyn.2018.09.007

\section{PUBLISHER}

(C) Elsevier

VERSION

AM (Accepted Manuscript)

\section{PUBLISHER STATEMENT}

This paper was accepted for publication in the journal Soil Dynamics and Earthquake Engineering and the definitive published version is available at https://doi.org/10.1016/j.soildyn.2018.09.007

LICENCE

CC BY-NC-ND 4.0

\section{REPOSITORY RECORD}

de Luca di Roseto, Alessandro, Alessandro Palmeri, and Alistair Gibb. 2019. "Performance-based Seismic Design of Steel Structures Accounting for Fuzziness in Their Joint Flexibility". figshare.

https://hdl.handle.net/2134/35744. 
This paper presents a performance-based earthquake engineering framework to explicitly take into account fuzziness in the design parameters, with application to steel structures. Semi-rigidity of column-to-foundation and beamto-column connections is considered as a relevant example of design parameters that can be properly modelled using fuzzy variables. Without lack of generality, their fixity factors are described by means of triangular membership functions, fully defined by lower and upper values of admissibility and their most likely value, i.e. their reference value. For demonstration purposes, the procedure is used to analyse two different case studies, namely a 5-storey single-bay plane frame and an industrial 3D modular structure. The analyses are performed accounting for the fuzziness of the connections, which is then propagated onto representative engineering demand parameters, within a general performance-based design (PBD) approach. Frank Gibb Building, Loughborough LE11 3TU, UK

\section{Keywords: Fuzzy variables, Modular structures, Performance-based design (PBD), Semi-rigid connections, Steel structures}

\section{Introduction}

In structural engineering design practice, steel connections are normally assumed either as perfectly rigid or frictionless pinned, in order to speed up and simplify the analyses. However, it is largely recognised that these idealised behaviours are practically unattainable in most cases, as in general the

\section{Performance-based seismic design of steel structures accounting for fuzziness in their joint flexibility}


connections tend to function as semi-rigid joints [1]. Furthermore, many experiments have shown that nonlinearity plays an important role in the actual behaviour of steel connections under ultimate load scenarios, which in turn depends on the progressive yielding of their components [2]. For this and other reasons (e.g. geometric imperfections, residual stress due to welding, stress concentration, the effects of frame nonlinearity, etcetera), the problem of the connection design is much more complicated than typically assumed in the day-to-day design practice. Furthermore, it is affected by a high level of uncertainty, such that over-simplifications may lead to considerable inaccuracies in the prediction of the structural responses of interest [3]. It should also be noted that the actual connections are very often detailed by the steel fabricator, rather than being specified by the structural engineering team responsible for the overall design of the structure, which is therefore affected by inherent uncertainties.

Over the last 40 years, flexible connections have been thoroughly investigated, trying to establish models and procedures able to take into account their behaviour when subjected to both static and dynamic loads [4-12]. However, these studies consider deterministic models and do not take into account any uncertainty related to semi-rigid connections, which inevitably affect the overall stiffness and capacity of the steel frame. However, modelling their uncertainties as random variables could be problematic, as reliable statistics can hardly be available. In this scenario, a non-probabilistic approach, incorporating the concept of "fuzziness" (rather than "randomness") is potentially an effective way to deal with uncertainties in the semi-rigid connections. Furthermore, this approach suits very well the common scenario in which the structural design has to be completed before the types of connections are specified, and sometimes even before the steel fabricator has been appointed. This means that only a form of expert judgement can be used to infer the "degree of belief" that a certain type of steel connection will be implemented. In this scenario, the stiffness and capacity of the connections cannot be effectively modelled as random variables, as neither the "frequentist" nor the "Bayesian" interpretation of probability (e.g. Ref. [13]) would be satisfactory. By contrast, fuzzy variables allow the designer to quantify, for instance, to what extent a nominal pin connection will result in certain values of rotational stiffness and bending capacity.

The fuzzy set theory was originally formalised in Zadeh's seminal work 
[14]. A fuzzy set is any set that allows its members to have different grades of membership in the interval $[0,1]$. The latter are defined mathematically through a so-called membership function (MF). An extensive discussion on fuzzy theory and its definitions and properties can be found in Refs. [15-18]. In recent years, many researchers have investigated the applicability of fuzzy uncertainties in structural engineering, including fragility analyses [19-22]. Fuzzy variables are particularly effective in representing the effects of "epistemic" uncertainty, i.e. caused by lack of knowledge and data, inaccuracy in the measurements or the intrinsic limitations of the model used, rather than "aleatory" uncertainty, due to irreducible randomness of a given phenomenon [23]. Stochastic approaches such as the random vibration theory or the stochastic finite element method are more appropriate for this second type of uncertainties. Potential advantages of fuzzy models include: $i$ ) simplicity and flexibility of implementation; $i i)$ ability to handle problems with imprecise and incomplete data sets; iii) possibility to model nonlinear functions of arbitrary complexity; $i v$ ) (relative) ease of development; $v$ ) lending themselves to task-parallelisation, which mitigates the time required to finalise the analyses.

It is worth mentioning here that various studies (e.g. [24-28]) have shown that the effects of epistemic uncertainty on structural models tend to be relatively small in comparison to the aleatory uncertainty in the seismic action, meaning that a deterministic structural model could be confidently adopted for design purposes. However, epistemic uncertainty might not always be negligible; this is the case, for instance, when the steel connections are detailed in a later structural design stage by a different design team, which is a customary practice for industrial modular structures [29].

In the present study, a performance-based procedure for the seismic analysis and design of steel structures with uncertain parameters is established, where the stiffness of beam-to-column and column-to-foundation connections is defined through MFs. This approach allows determining "defuzzified" design values of the selected engineering demand parameters (EDPs). These can be used to quantify rigorously the effects of this source of uncertainty in conjunction with the aleatory randomness of the seismic hazard, even with an affordable computational effort. 


\section{Performance-based design}

The end of the 20th century has seen an increased research effort toward improving earthquake engineering analysis and design, particularly through procedures able to take into account the seismic hazards in the performance assessment of a structure, balancing scientific rigour and engineering viability in design practice.

One important reason that pushed engineers to look for alternatives to prescriptive seismic design codes is that, although they appear to provide sufficient protection against the no-collapse requirement, i.e. safeguarding the users' life in case of events with a relatively high return period, the economic losses caused by structural damage and from the loss of the use of facilities in case of moderate events, comparatively with a lower return period, proved often to be disproportionally high [30]. Indeed, the traditional prescriptive codes of seismic design are primarily focused on structural resistance and, as such, require a pre-defined minimum value for the demand-to-capacity ratio (D/C), which ensures life safety and, as a by-product, damage control. Taking a completely different approach, the explicit goal of performance-based design (PBD) is to achieve a desired level of performance that is directly correlated to appropriate consequences and, ideally, can be agreed upon discussion with the client and the relevant stakeholders. Performance can then be quantified in different ways, including monetary costs, considering for instance both initial investments and likely maintenance costs [31].

Another important difference between PBD and traditional prescriptive design consists of the steps that are required to approach the structural problem. Whereas in traditional methods the level of seismic risk and the acceptable level of damage are implicitly established by the design codes, in PBD they are explicitly determined during the design process, taking into account the desired performance levels [31], which in turn are inevitably affected by any source of uncertainly in the design problem.

Since the early 2000s, the Pacific Earthquake Engineering Research (PEER) centre started developing a new performance-based earthquake engineering (PBEE) methodology. Building on the first PBD generation [32], the innovative key feature of the PEER's PBEE approach is that the performance is rigorously defined in a probabilistic manner. The framework consists of four main stages that can be performed in cascade, namely: $i$ ) hazard, $i i$ ) 
structural, iii) damage and $i v$ ) loss analysis. At the end of these, the obtained quantitative data allow decision makers to identify an "optimal" solution, in whichever sense is most appropriate for each particular design. The framework is typically expressed mathematically through the following triple integral [33]:

$$
\begin{gathered}
p[D V \mid\{O, D\}]=\iiint p[D V \mid D M] \cdot p[D M \mid E D P] \cdot p[E D P \mid I M] \\
\cdot p[I M \mid\{O, D\}] \mathrm{d} I M \mathrm{~d} E D P \mathrm{~d} D M
\end{gathered}
$$

where $p[X]=$ probability density function (PDF) of the random variable $X$; $p[X \mid Y]=$ conditional PDF (CPDF) of $X$ given the event $Y ; O=$ location of the structure; $D=$ design of the structure; $I M=\mathrm{IM}$ of the earthquake; $E D P=\mathrm{EDP}$, as a measure of the structural response; $D M=$ measure of any physical damage; $D V=$ decision variable, that is the performance parameter of interest.

If the structure is affected by fuzzy uncertainties, the random variable $E D P$ in Eq. 1 is rigorously described by a CPDF with fuzzy statistical descriptors, and then this type of imprecise probability is propagated onto both $D M$ and $D V$.

\section{Semi-rigid connections}

Beam-to-column and column-to-foundation connections are usually subjected to a combination of axial force, shear force and bending moment. However, since for the majority of them the axial and shear deformations are small compared to the flexural ones, only the rotational behaviour caused by flexural actions will be considered in what follows. In certain circumstances, however, shear deformations can significantly affect the strength, stiffness and the ductility of a steel frame subjected to earthquake excitations, namely when the panel zone in some of the connections prove to be weak in shear (e.g. Refs. [34-36]).

The nonlinear behaviour of a connection can be shown in a momentrotation $\left(M-\phi_{c}\right)$ diagram, where $\phi_{c}$ is the rotation at the joint due to the inherent flexibility of the connection. Figure 1(a) represents typical $M-\phi_{c}$ curves for several common connections. The two extreme cases, 


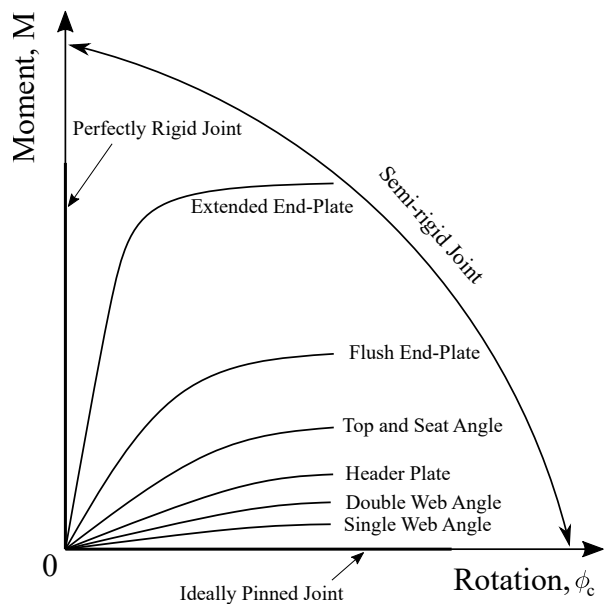

Figure 1: Typical $M-\phi_{c}$ curves for several common connections (adapted from [2])

ideally pinned and perfectly rigid, correspond to the horizontal and the vertical line, respectively [2]. For instance, the single-web connection represents an example of flexible joint, while T-stub connections, with their extended end plates, are rather stiff. Accordingly, to reach the same value of rotation $\phi_{c}$, the former type of connection will require an end moment $M$ significantly larger than the latter one. Different models can be used to predict the $M-\phi_{c}$ curve of the joint behaviour. Ref. [37] summarises the most commonly used models, which can be grouped into: analytical (e.g. [7, 38, 39]), empirical (e.g. [40-42]), experimental (e.g. [43-45]), mechanical (e.g. [38, 46]), numerical (e.g. [47-49]) and information-based models (e.g. [50-52]).

From a mathematical point of view, semi-rigid connections can be modelled through link elements ideally placed between beams and columns or at the base of the columns. The links act as rotational springs, which are typically used to model the effects of connection flexibility onto the overall stiffness matrix of the structure. In particular, the rotational stiffness $k_{c}$ of a semi-rigid connection can be conveniently expressed as:

$$
k_{c}(\nu)=\frac{3 E I}{l} \frac{\nu}{1-\nu},
$$

where $E, I, l, \nu$ are the Young's modulus, moment of inertia, length of the steel member (beam or column) and the dimensionless fixity factor, respectively. The latter can be defined as in Ref. [53, 54], and it is always 


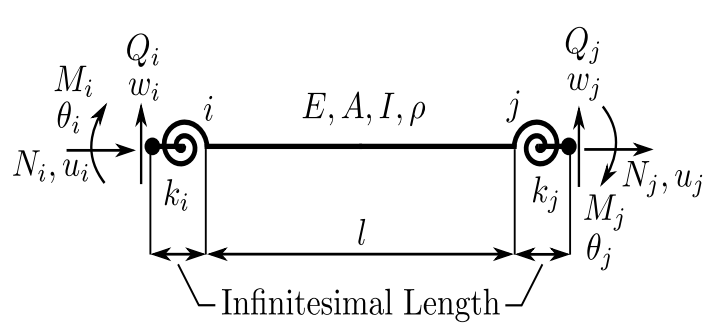

(a)

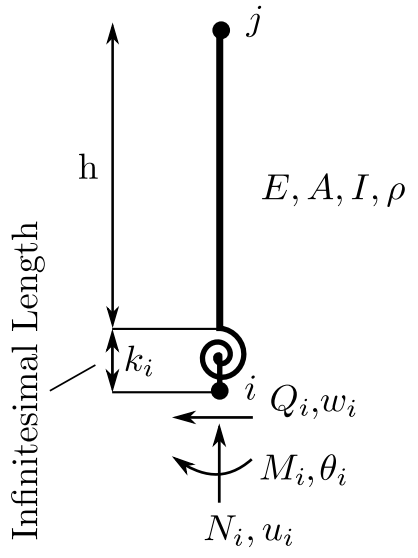

(b)

Figure 2: (a) Beam with rotational springs; (b) Column with base rotational spring

within the range $[0,1]$. The two limiting cases, $\lim _{\nu \rightarrow 1} k_{c}(\nu)=+\infty$ and $\lim _{\nu \rightarrow 0} k_{c}(\nu)=0$, represent a rigid connection (restraining rotation) and a pinned connection (permitting free rotation), respectively.

\section{Fuzzification of the fixity factor}

Recent years have seen an increasing interest among researchers and practitioners in the applications of non-probabilistic methods to engineering problems affected by uncertainty [55-58]. Among them, fuzzy logic has a prominent role. Unlike randomness, fuzziness describes ambiguity in an event, attempting to measure the degree to which it occurs, not whether it occurs [59]. Even though fuzzy logic makes use of similar concepts as the probability theory, the final scope is different. As a matter of fact, probability theory deals with a collection of "well" defined events and make predictions on the chance of occurrence of each event, while fuzzy set theory deals with a collection of "vague" events, assigning to them certain degrees of "belongingness" that are represented through the so-called "membership functions" (MFs) [60].

Considering a space of points $X$, with a generic element $x \in X$, the MF $\mu(x)$ associates $x$ to a real number in the interval $[0,1]$, which represents the "grade of membership" of $x$ [14]. Obviously, the higher $\mu(x)$, the higher the 


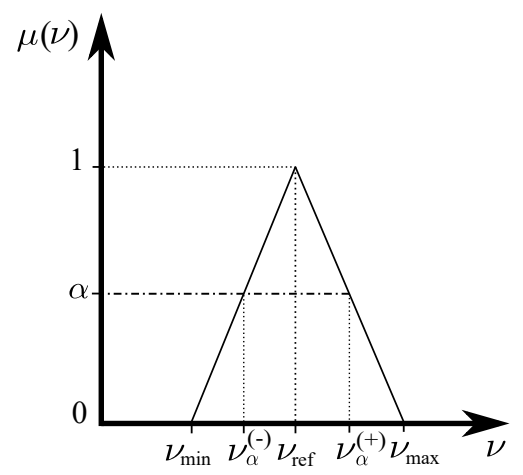

Figure 3: Triangular membership factor (MF) of a fixity factor

degree of truth for that particular value $x$.

In this paper, the fixity factors of beam-to-column $\left(\nu_{b c}\right)$ and column-tofoundation $\left(\nu_{c f}\right)$ connections are assumed to be uncertain and defined by means of fuzzy variables with triangular MFs, such as the one depicted in Figure 3. More complicated shapes can be used for the MFs of the input variables; however, this would require the availability of more information, which might be difficult to obtain in real-life design situations. For this reason, without affecting the generality and practical viability of the proposed procedure, only triangular MFs will be considered for $\nu_{b c}$ and $\nu_{c f}$. That is, the MFs $\mu(\nu)$ for the fixity factors are built considering three values, namely $\nu_{\min }, \nu_{\text {ref }}$ and $\nu_{\max }$ : the first and third values are, respectively, the lower and upper bound of the range of fixity factors values which are considered to be realistically possible, and they are associated to MF equal to zero; while the other value, $\nu_{r e f}$, is the reference value, e.g. the most likely one, for which the MF is taken equal to one. Clearly, as a consequence of the fuzzification of the semi-rigid connections, also the structural response in terms of EDPs, e.g. internal forces, absolute accelerations and displacements, are fuzzy variables, fully defined by their MFs.

As shown in Figure 3, in addition to the values $\nu_{\min }, \nu_{\text {ref }}$ and $\nu_{\max }$ already mentioned above, there are other values resulting from a MF being cut at a given ordinate $\alpha \in[0,1]$. The fuzzy set containing all elements with a MF of $\alpha$ and above is called the $\alpha$-cut of the MF [61]. Obviously, one can make as many $\alpha$-cuts as desired on the MF of the design variables, and then the corresponding $\alpha$-cuts in the EDPs, DMs and DVs can be determined. 


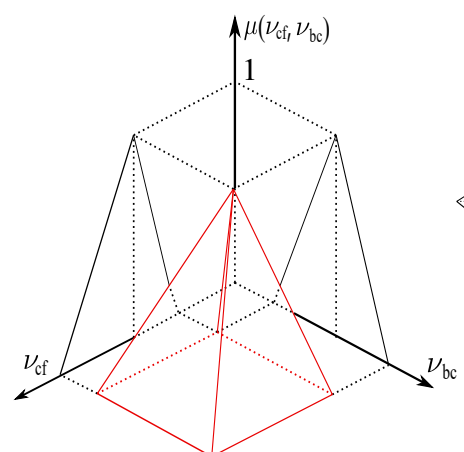

(a)

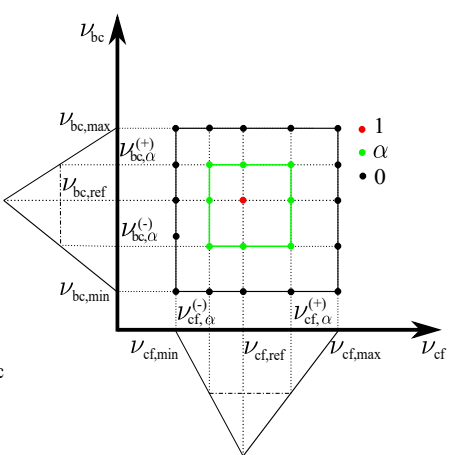

(b)

Figure 4: Pyramidal membership function (MF): (a) 3D view; (b) top view

The definition of triangular MFs for the two fixity factors $\nu_{b c}$ and $\nu_{c f}$ results into a pyramidal MF in the three-dimensional space $\left\{\nu_{b c}, \nu_{c f}, \mu\right\}$, as shown in Figure 4, where the $\alpha$-cuts become horizontal planes characterised by the same value of MF. If $n_{d} \geq 3$ design parameters need to be described through fuzzy variables, then the overall MF will be represented mathematically by an $\left(n_{d}+1\right)$-dimensional hyperpyramid, and any $\alpha$-cut will be described by an $n_{d}$-dimensional hyperplane orthogonal to the $\mu$ axis.

For the MF of Figure 4, adopting the so-called "vertex method" [62], each vertex $\left\{\nu_{c f}, \nu_{b c}\right\}$ derived from the combination of the values of the two fixity factors can be used to define a particular realisation of the structural model and therefore corresponds to a structural analysis. Importantly, the $\alpha$-cut value of the MF of any EDP delivered by the structural analysis is the same as the value of the MF of the input fuzzy variables, i.e. input and output parameters have the same degree of membership. Once the largest and smallest values of each output parameter are calculated for each $\alpha$-cut level, its MFs can be constructed.

It should be noted here that the vertex method provides a good approximation of the actual MF of the output parameters only if the input-output functional relationship is continuous and monotonic [62]. If these conditions are not met, other methods can be used, e.g. heuristic optimisation algorithms (such as genetic algorithms, particle swarm, ant colony, etcetera) or response surfaces. The procedure used to calculate the MF of the design quantities of interest will depend, in practical applications, on the complexity 


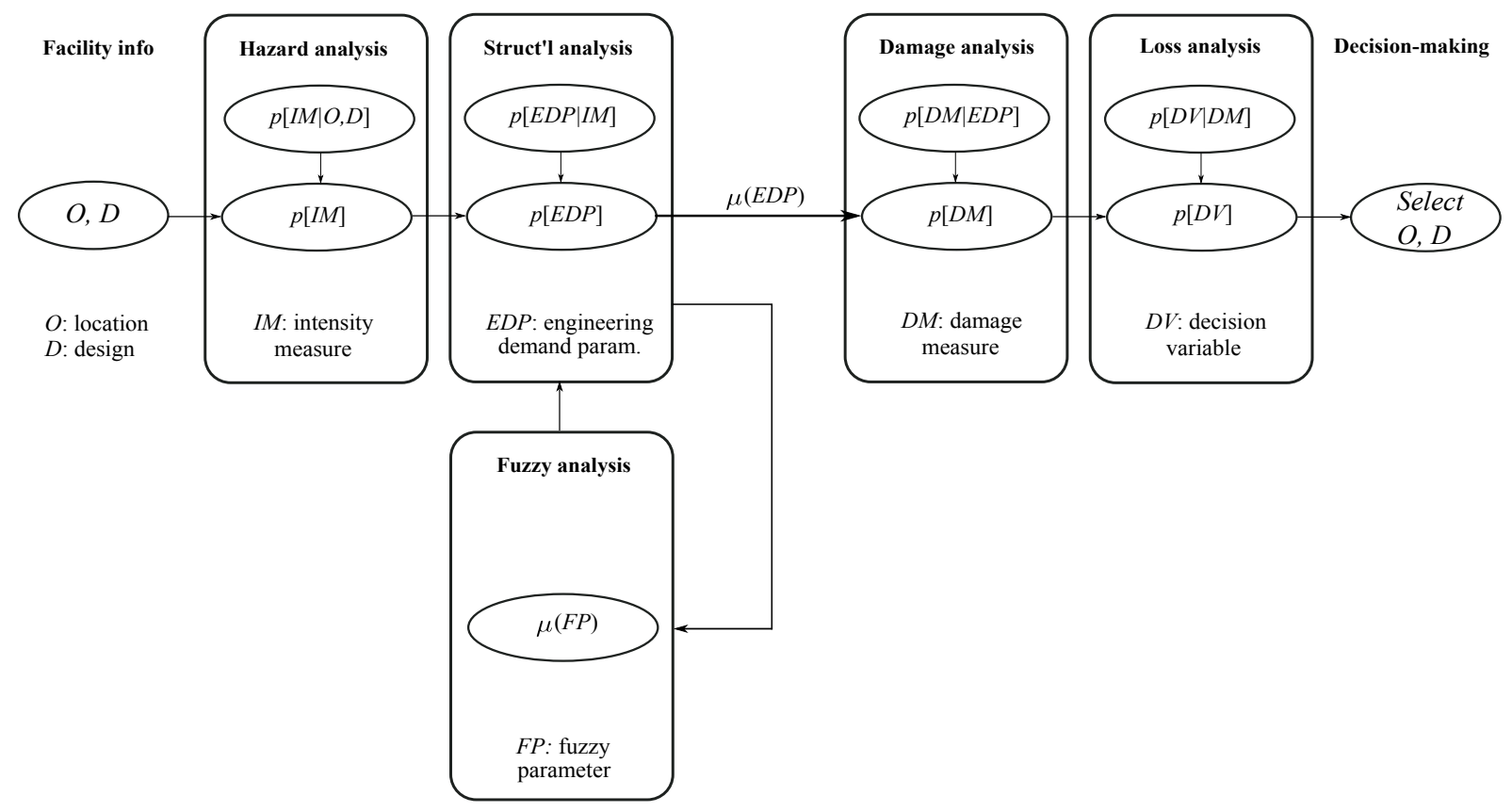

Figure 5: Performance-based fuzzy design (PBFD) framework

of the structural problem, the availability of data and the required accuracy.

\section{Fuzzy analysis as a part of a fuzzified PBD framework}

Once the fuzziness has been introduced into the design parameters, the classical PEER's framework for the PBD can be extended, introducing a fuzzy analysis as part of the structural analysis, as illustrated in Figure 5.

Aimed at demonstrating the practical applicability of the proposed approach as part of the day-to-day design practice, the seismic analysis of two case-study structures has been performed with the commercial structural analysis program SAP2000 [63], exploiting its OAPI (open application programming interface), which allows SAP2000 to be used in conjunction with other software, including a general-purpose numerical computing environment such as MATLAB [64]. The steps required by the proposed fuzzy seismic analysis are highlighted in the following paragraphs, and the numerical results are presented and discussed in detail in the Section 6 . 
In order to apply the fuzzified PBD approach, the first stage is the characterisation of the seismic hazard. This is typically done through the "hazard curve", which gives the probability of exceedance (PoE) in $N$ years of the chosen IM, with both $N$ and the IM being chosen by the designer to fit the particular structural project being considered and the availability of data for the construction site. The hazard curve is then discretised in a certain number of IM levels, $n_{I M}$, and $n_{E Q}$ earthquake records are used to represent the seismic action for each of these levels. Importantly, the number and values of the IM levels $I M_{1}, I M_{2} \cdots, I M_{n_{I M}}$ must be carefully chosen to allow quantifying the effects of seismic events with a range of probabilities of occurrence, while $n_{E Q}$ should be large enough to provide a sufficient statistical variability for a given IM level. In total, a set of $n_{H A Z}=n_{I M} n_{E Q}$ earthquake records will be required to fully describe the seismic hazard, and typically $n_{H A Z} \geq 50$.

Once the set of earthquake records has been established, the proposed fuzzified version of the PBD requires that a time-history dynamic analysis is carried out for each of the $n_{H A Z}$ earthquake records (which describe the aleatory variability of the seismic hazard) and each of the $n_{S T R}$ combination of the $n_{d}$ fuzzy design parameters (which describe the epistemic uncertainty in the structural model). Considering that a $n_{d}$-dimensional hypercube has $n_{V E R}=2^{n_{d}}$ vertexes, the number of structural model combinations is:

$$
n_{S T R}=1+n_{V E R}\left(n_{\alpha}-1\right),
$$


where $n_{\alpha}=$ number of $\alpha$-cuts, including $\alpha=0$ and $\alpha=1$. Notably, each structural model variation corresponds to a combination of the input variables in which every one of them takes an extreme value, i.e. either the minimum or maximum value that the designer considers as realistically possible. Depending on the complexity of the structural problem, additional combinations could be considered for each $\alpha$-cut level, e.g. one for each edge or each square in the $n_{d}$-dimensional hypercube defining the variability of the design variables. For instance, it can be shown that the number of edges is $n_{E D G}=n_{d} 2^{n_{d}-1}\left(n_{d} \geq 2\right)$ and the number of squares is $n_{S Q R}=n_{d}\left(n_{d}-1\right) 2^{n_{d}-3}\left(n_{d} \geq 3\right)$, so that the number of structural model combinations becomes, respectively:

$$
\begin{aligned}
& n_{S T R}=1+\left(n_{V E R}+n_{E D G}\right)\left(n_{\alpha}-1\right) ; \\
& n_{S T R}=1+\left(n_{V E R}+n_{S Q R}\right)\left(n_{\alpha}-1\right) .
\end{aligned}
$$

Once all the dynamic analyses have been executed, the whole set of values is obtained for the EDPs of interest, say $E D P_{i h j \ell k}$, where $i$ denotes the $i$ th EDP required for the subsequent stages of the PBD, i.e. damage and loss analyses; $j=1,2, \cdots, n_{E Q}$ denotes the $j$ th earthquake record for the $h$ th level of the IM of the seismic risk (with $h=1,2, \cdots, n_{I M}$ ); $k$ denotes the $k$ th combination of the fuzzy design variable for the $\ell$ th $\alpha$-cut level.

It can be noted that, for a given level of the seismic hazard $I M_{h}$ and within the theoretical framework of imprecise probabilities [65], $E D P_{i h j \ell k}$ represents the generic realisation of a random variable with fuzzy statistical parameters. As such, $E D P_{i}$ is fully described by the $I M$-dependent membership functions of its statistical descriptors, such as its mean value, variance, higher-order cumulants, fractiles, etcetera.

Although appealing from a theoretical standpoint, this kind of representation is impractical in the everyday design practice. For this reason, a different approach is pursued here:

1. For each of the $n_{S T R}$ combinations $\{\ell, k\}$ of the fuzzy design variables, the CPDF $p\left[E D P_{i \ell k} \mid I M_{h}\right]$ is best fitted to the empirical set of $n_{E Q}$ realisations $\left\{E D P_{i h 1 \ell k}, E D P_{i h 2 \ell k}, \cdots, E D P_{i h n_{E Q} \ell k}\right\}$.

2. Said $\Pi_{i h \ell k m}$ the $m$ th statistical descriptor of $p\left[E D P_{i \ell k} \mid I M_{h}\right]$, with $m=1,2, \cdots$ depending on the complexity of the model adopted for the CPDF, the $n_{I M}$ pairs $\left\{I M_{h}, \Pi_{i h \ell k m}\right\}$ are best fitted with a poly- 
nomial function. In this way the statistical descriptor $\Pi_{i \ell k m}(I M)$ can be evaluated for any value of the IM, not just the discrete values $I M_{h}$; for instance, for each of the four performance levels (PLs) [66] known as "operational" (O), "immediate occupancy" (IO), "life safety" (LS) and "collapse prevention" (CP). In the following, the generic CCDF (conditional cumulative distribution function), defined as:

$$
F\left[E D P_{i \ell k} \mid I M\right]=\int_{-\infty}^{E D P_{i \ell k}} p\left[E D P_{i \ell k} \mid I M\right] \mathrm{d} E D P_{i \ell k},
$$

will be referred to as "response curve" of the specific $i$ th EDP and structural model combination $\{\ell, k\}$ being considered.

3. Finally, the "design curve" for the $i$ th EDP at a given level of seismic IM can be obtained by building the MF of the generic $Y$ th fractile of the fuzzy random variable $E D P_{i}(I M)$, say $\mu_{E D P_{i, Y}(I M)}$, and extracting a "design value" from it, say $X=E D P_{i, Y}^{*}(I M)$, where the superscripted asterisk denotes here a defuzzified quantity. The parametric plot of the pair $\{X, Y\}$ for $0 \leq Y \leq 1$ defines the sought design curve. Importantly, although the actual design curve varies with the chosen method used to defuzzify the design variable, the overall framework does not depend on it.

\section{Performance-based fuzzy design: numerical examples}

For demonstration purposes, the proposed performance-based fuzzy design (PBFD) framework has been applied to two different structures of increasing complexity, namely a planar frame and an industrial 3D modular structure. Hazard, structural and fuzzy analyses have been performed on both cases, whereas damage and loss analyses have not been carried out, as their practical implementation is very similar to the calculation of the EDPs. In both cases, the structures are assumed to be designed for a site in California, at latitude $37.8^{\circ}$ North and longitude $122.417^{\circ}$ West, corresponding to a site near San Francisco, that happens to be a class "B" (firm rock), in agreement with the classification map reported in Ref. [67]. 
Table 1: Geometrical properties of the steel members in the first numerical example

\begin{tabular}{l|r|r} 
& $A\left[\mathrm{~m}^{2}\right]$ & $I\left[\mathrm{~m}^{4}\right]$ \\
\hline Columns & $254 \times 10^{-3}$ & $1,367 \times 10^{-6}$ \\
\hline 1st- and 2nd- storey beams & $156 \times 10^{-3}$ & $921 \times 10^{-6}$ \\
\hline 3rd- to 5th- storey beams & $134 \times 10^{-3}$ & $671 \times 10^{-6}$ \\
\hline
\end{tabular}

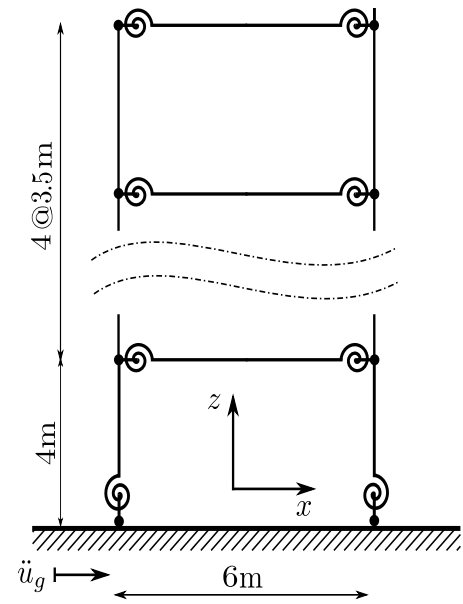

Figure 6: Structural model for the first numerical example

\subsection{Case study \#1: 5-storey frame structure}

Figure 6 shows the first case-study model consisting of a 5-storey single-bay frame adapted from $[10,54]$. The material is steel, with Young's modulus $E=210 \mathrm{GPa}$. The geometrical properties are listed in Table 1. Each beam element has lumped masses $M=3.5 \mathrm{Mg}$ at its nodes, representing the effects of dead, super-dead and imposed load.

The values $\nu_{c f}=0.16$ and $\nu_{b c}=0.84$ have been chosen as reference values for the fixity factors of the two types of connections. In particular, $\nu_{b c}=0.84$ could correspond to the fixity factor of either a T-stub or an extended endplate connection [2]. This choice might correspond to a scenario in which the structural engineering design team has envisaged a steel frame with nearlypinned connections at the base of the columns and nearly-rigid connections at the ends of the beams. The resulting fundamental period of vibration is $T_{1}=0.90 \mathrm{~s}$. The latter will be denoted in the following as the reference value of the fundamental period of vibration, i.e. $T_{1, \text { ref }}$. 
Triangular MFs have been built for the fixity factors in the range of $\pm 15 \%$ with respect to the reference values. This means that the ratio between the base of the triangle and the reference value of the MF (known as "amplitude ratio", AR) is always equal to 0.3. Although relatively high, this level of fuzziness is realistic when one considers the uncertainty associated with the detailing and fabrication of the connections. In practice, expert judgment should be used in the design stage, e.g. based on previous projects involving various steel fabricators, to provide a more stringent definition of the range of variability for the stiffness of the connections. Also, without precise indications on the reference value for $\nu_{c f}$ and $\nu_{b c}$, trapezoidal rather than triangular MFs could be used instead.

As shown in Figure 7(a) and (b), only two $\alpha$-cut levels have been considered in this numerical application, namely: $\alpha=0$ and $\alpha=1$. As a result, nine structural model combinations were determined (Fig. 7(c)), considering for $\alpha=0$ one combination for each vertex and one further combination for each edge (see Eq. (3b)). All the combinations of fixity factors used for the structural analyses are listed in Table 2, along with the corresponding values of the fuzzy fundamental period of vibration $T_{1}$.

Figure 8 shows the MF of $T_{1}$. As expected, the largest value of $T_{1}=$ $0.996 \mathrm{~s}$ is achieved when both fixity factors take the minimum values allowed by their MFs (combination \#3); similarly, the smallest value of $T_{1}=0.830 \mathrm{~s}$ occurs when the fixity factors are equal to their maximum permitted values (combination \#9). Since for $T_{1}$ the $\mathrm{AR}$ is equal to 0.184 , one can conclude that, compared to the input ARs, there is an uncertainty reduction equal to $(0.300-0.184) / 0.300=39 \%$. This confirms the assumption that relatively moderate variations can be expected for the value of $T_{1}$, and thus the spectral acceleration $S_{a}\left(T_{1, r e f}\right)$ appears as an effective choice for the IM of the seismic hazard.

\subsubsection{Hazard curve}

The first stage in the application of the PBFD framework consists in the definition of the probabilistic seismic hazard, $p[I M \mid\{O, D\}]$, considering all the design parameters related to the location, including magnitude, faults and soil conditions. The spectral acceleration at the period of the first mode, $S_{a}\left(T_{1}\right)$, has been chosen as the IM of the seismic hazard, as this quantity 


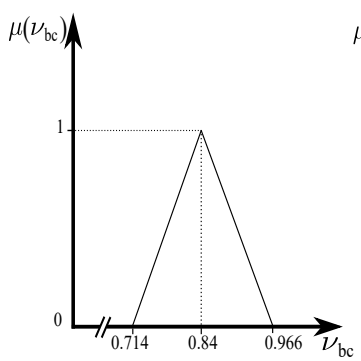

(a)

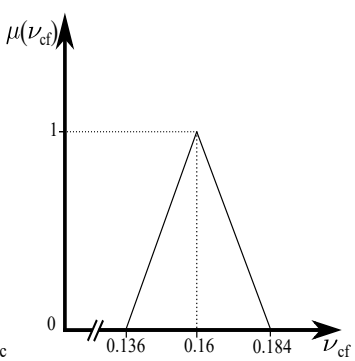

(b)

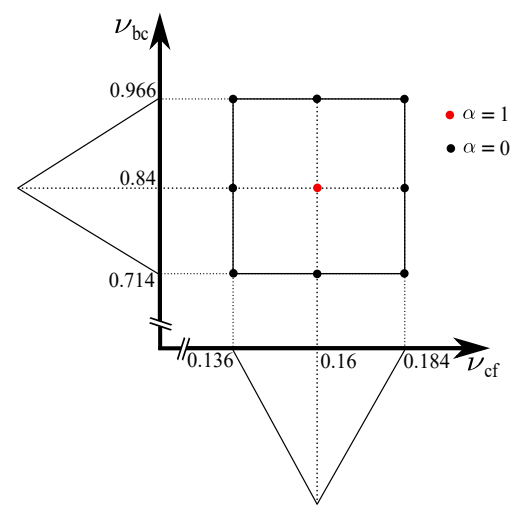

(c)

Figure 7: Membership functions for the first numerical example: (a) beam-to-column connections; (b) column-to-foundations connections; (c) top view of the pyramidal function

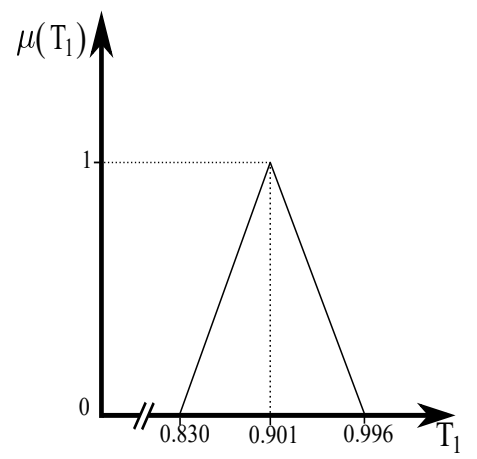

Figure 8: Membership function of the fundamental period $T_{1}$ for the first numerical example 
Table 2: Combinations of the fixity factors in the first numerical example

\begin{tabular}{c|r|r|r} 
Combination \# & $\nu_{c f}$ & $\nu_{b c}$ & $T_{1}[\mathrm{~s}]$ \\
\hline 1 & 0.16 & 0.84 & 0.901 \\
\hline 2 & 0.136 & 0.84 & 0.917 \\
\hline 3 & 0.136 & 0.714 & 0.996 \\
\hline 4 & 0.136 & 0.966 & 0.851 \\
\hline 5 & 0.16 & 0.714 & 0.982 \\
\hline 6 & 0.16 & 0.966 & 0.840 \\
\hline 7 & 0.184 & 0.84 & 0.894 \\
\hline 8 & 0.184 & 0.714 & 0.970 \\
\hline 9 & 0.184 & 0.966 & 0.830 \\
\hline
\end{tabular}

tends to be better correlated to the EDPs than the peak ground acceleration (PGA) (e.g. Ref. [68]). Additionally, since moderate variations are expected in the dependent fuzzy variable $T_{1}$, the same sets of earthquake records can be used for all the time-history analyses, irrespective of any model variation due to the fuzzy design variables.

In this study, the hazard curve, expressed in the form of $S_{a}\left(T_{1, r e f}\right)$ against the PoE in 50 years, has been built with the OpenSHA software [69]. The hazard curve has then been divided into ten groups, each one characterised by $10 \%$ variations in the PoE (i.e. $n_{I M}=10$ ), whose midpoints are marked with red thick dots in Fig. 9).

\subsubsection{Ground motion data set}

Once the hazard curve has been established, a database of 150 earthquake records has been created to be used for the nonlinear time-history analyses. The accelerograms, recorded at 63 different stations in California, all on firm rock, have been downloaded from the NGA-West2 PEER's ground motion database [70]. The 5\%-damping response spectra of the earthquake records have been scaled with respect to the values of spectral acceleration $S_{a}\left(T_{1, \text { ref }}\right)$ corresponding to each midpoint of the $10 \mathrm{PoE}$ intervals previously defined for the hazard curve (see Table 3). The scale factors have been computed for all the 150 accelerograms and all the 10 IM levels, and only the best 7 with scale factors closer to 1 for each IM level have been used for the time-history 


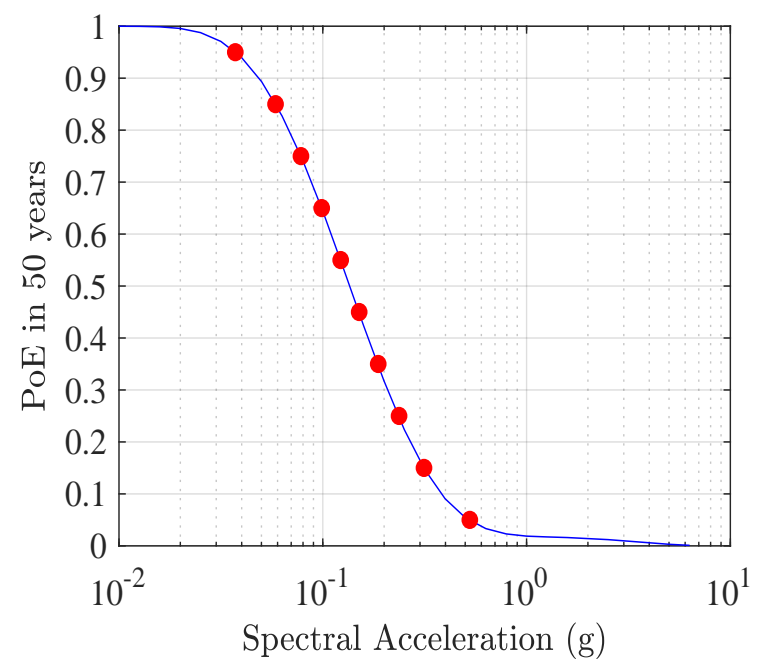

Figure 9: Hazard curve of the first numerical example

analyses, i.e. $n_{E Q}=7$. The latter value has simply been chosen because international seismic codes [71-73] typically require a minimum number of 7 time-history analyses for estimating the median of the structural response of interest although it should be noted here that, in contrast with the same code requirements, no compatibility rules and/or matching procedures have been applied to the earthquake spectra as part of the numerical examples). Figure 10(a) shows the average scaled response spectra for each IM level, while Figure 10(b) demonstrates the variability of the response spectra for the accelerograms used to define the seismic hazard at a given IM level, namely the highest level, i.e. $S_{a}\left(T_{1, r e f}\right)=0.526$ g. Alternative and more sophisticated procedures exist, that could have been implemented for the selection and/or the artificial generation/modification of accelerograms (e.g. Refs. [74-78]), including compatibility with and/or matching to a given set of design spectra. Such procedures, however, do not directly affect the application of the proposed fuzzy version of the PEER's PBEE framework, which is independent of the particular suite of earthquake records used for representing the seismic hazard. For the purposes of the present work, in particular, the adopted procedure appears to provide a sufficient level of record-to-record variability (as demonstrated by the response spectra of Figure 10(b), for instance). 


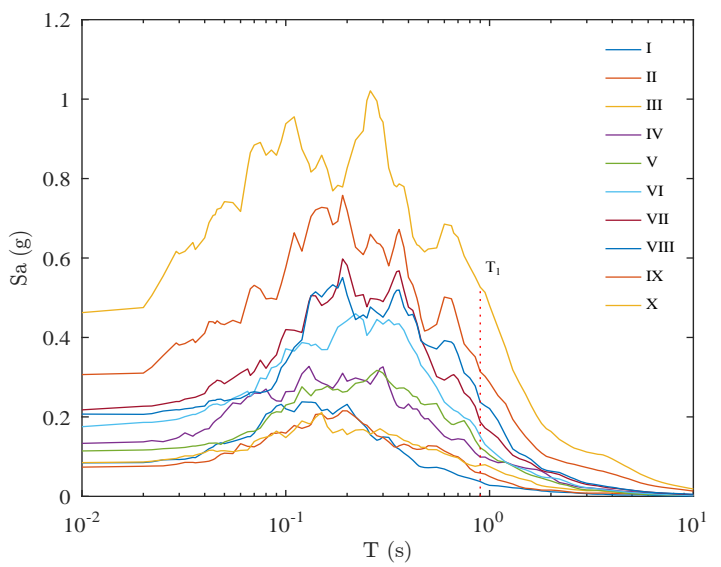

(a)

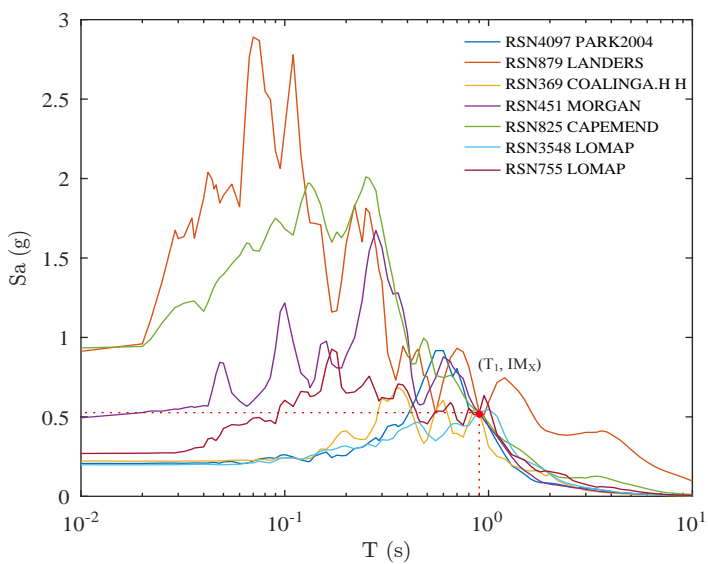

(b)

Figure 10: Hazard analysis: (a) average response spectra for each IM level; (b) response spectra for $I M_{10}$ 
Table 3: IM levels for the hazard curve of the first numerical example

\begin{tabular}{c|r} 
IM level & $S_{a}\left(T_{1_{r} e f}\right)[\mathrm{g}]$ \\
\hline I & 0.0372 \\
\hline II & 0.0586 \\
\hline III & 0.0781 \\
\hline IV & 0.0988 \\
\hline V & 0.122 \\
\hline VI & 0.151 \\
\hline VII & 0.187 \\
\hline VIII & 0.237 \\
\hline IX & 0.314 \\
\hline X & 0.526 \\
\hline
\end{tabular}

Table 4: Probability of exceedance in 50 years for the four performance levels considered in the structural analysis, and corresponding spectral accelerations in the hazard curve for the first numerical example

\begin{tabular}{c|r|r} 
Performance level & $P o E_{50}[\%]$ & $S_{a}\left(T_{1, r e f}\right)[\mathrm{g}]$ \\
\hline O & 50 & 0.14 \\
\hline IO & 20 & 0.27 \\
\hline LS & 10 & 0.40 \\
\hline CP & 2.0 & 1.00 \\
\hline
\end{tabular}

\subsubsection{Structural analysis}

Once the accelerograms were defined consistently with the hazard analysis, the probabilistic characterisation of the structural response, $p[E D P \mid I M]$, has been achieved for the $n_{S T R}=9$ structural model variations obtained considering the different combinations of the fuzzy fixity factors. For illustration purposes, EDPs belonging to two different damageable groups have been considered, namely structural and non-structural components, i.e. the maximum bending moment (MBM) of the beam at the 1st floor and the peak absolute accelerations (PAA) and the peak displacement (PD) at the top floor. Table 4 shows the damage level (DL) considered for the response curves, with the corresponding values of the spectral acceleration, from 0.14 to $1.00 \mathrm{~g}$. 
Table 5: Lower bound, reference value and upper bound of the median of the maximum bending moment (MBM) in the first numerical example

\begin{tabular}{c|r|r|r|c} 
Performance level & $\begin{array}{c}M B M_{50, \text { min }} \\
{[\mathrm{kNm}]}\end{array}$ & $\begin{array}{c}M B M_{50, \text { ref }} \\
{[\mathrm{kNm}]}\end{array}$ & $\begin{array}{c}M B M_{50, \text { max }} \\
{[\mathrm{kNm}]}\end{array}$ & $\mathrm{AR}$ \\
\hline $\mathrm{O}$ & 233.46 & 280.39 & 344.05 & 0.39. \\
\hline $\mathrm{IO}$ & 401.85. & 460.17. & 537.81. & 0.30. \\
\hline $\mathrm{LS}$ & 556.24. & 618.99. & 702.61. & 0.23. \\
\hline $\mathrm{CP}$ & 1186.66 & 1235.58 & 1310.15. & 0.10. \\
\hline
\end{tabular}

Table 6: Lower bound, reference value and upper bound of the 90th fractile of the maximum bending moment (MBM) in the first numerical example

\begin{tabular}{c|r|r|r|c} 
Performance level & $\begin{array}{c}M B M_{90, \text { min }} \\
{[\mathrm{kNm}]}\end{array}$ & $\begin{array}{c}M B M_{90, \text { ref }} \\
{[\mathrm{kNm}]}\end{array}$ & $\begin{array}{r}M B M_{90, \text { max }} \\
{[\mathrm{kNm}]}\end{array}$ & $\mathrm{AR}$ \\
\hline $\mathrm{O}$ & 374.97 & 396.32 & 506.02 & 0.33 \\
\hline $\mathrm{IO}$ & 688.39 & 729.94 & 843.08 & 0.21 \\
\hline $\mathrm{LS}$ & 1003 & 1046.8 & 1138.6 & 0.13 \\
\hline $\mathrm{CP}$ & 2323 & 2437 & 2492 & 0.07 \\
\hline
\end{tabular}

6.1.3.1. Maximum bending moment. After computing the 9 MBM response curves for each of the 9 structural model variations, the MF of their median and 90th fractile has been established. Although the analyses have been performed for all the DLs listed in Table 4, the results in terms of CDFs for the two EDPs are presented herein only for the performance levels of IO (i.e. PoE of $20 \%$ in 50 years) and CP (i.e. PoE of $2.0 \%$ in 50 years). Interestingly, in all the analyses conducted, the shape of the MF of the median always appears to be very close to an isosceles triangle, with the AR decreasing at higher levels of the IM. This is due to the fact that the larger the seismic forces, the more significant the importance of the yield moment of the steel members, which however have not been fuzzified and thus does not contribute to further enlarge the base of the MF. Different is the behaviour of the MF for the 90th fractile, which is always a scalene triangle, i.e. pronouncedly asymmetrical, meaning that in this case the centroid of the MF can be relatively distant from the reference value $M B M_{r e f}(I M)$ for which $\mu_{M B M(I M)}=1$, i.e. the deterministic case that would obtained by neglecting the fuzziness in the steel connections. 


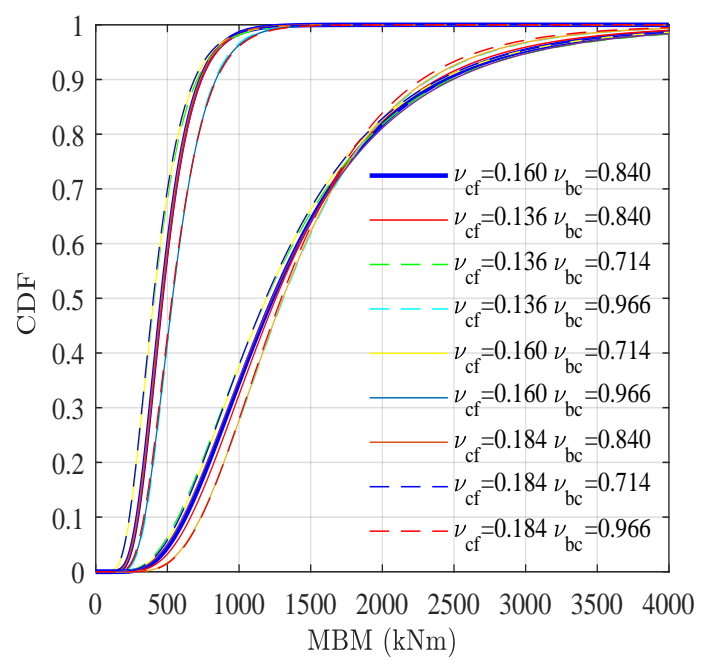

(a)

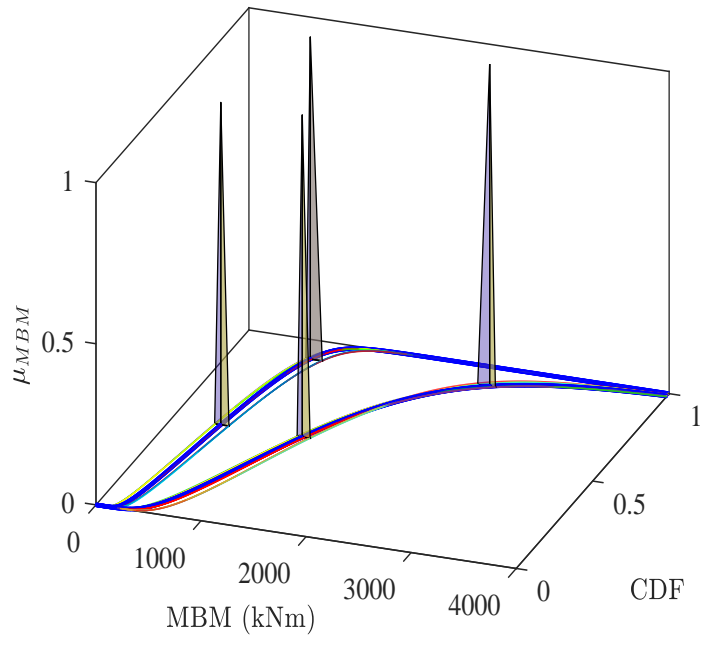

(b)

Figure 11: IO (immediate occupancy) and CP (collapse prevention) performance levels for the maximum bending moment (MBM) in the first numerical example: (a) response curves; (b) membership functions of median and 90th percentile

6.1.3.2. Peak absolute acceleration. Differently from what has been seen for the MBM, the MFs of the median and 90th fractile of the PAA follow approximately the same trend with the variation of the IM. The only exception is the case of the CP performance level, as both MFs are right-angled triangles, but the vertical side corresponds to the upper bound for the median, i.e. $P A A_{50, \min }(I M)=P A A_{50, \text { ref }}(I M)$, and to the lower bound for the 90th fractile, i.e. $P A A_{90, \min }(I M)=P A A_{90, \text { ref }}(I M)$. This is indeed an interesting result, as it shows that the deterministic assessment of an EDP can either be under- or over-conservative. Obviously, more refined results could be achieved using: $i$ ) more earthquake records for a given value of the IM; ii) more $\alpha$-cuts.

6.1.3.3. Peak displacement. For the sake of completeness, the MFs of the median and 90th fractile of the PD have also been established, which follow a very similar trend as the MFs of the PAA. In this case, however, only the MF of the 90th fractile is a right-angled triangle, with the vertical side corresponding to lower bound, i.e. $P D_{90, \min }(I M)=P D_{90, \text { ref }}(I M)$. It is 
Table 7: Lower bound, reference value and upper bound of the median of the peak absolute acceleration (PAA) in the first numerical example

\begin{tabular}{c|r|r|r|r} 
Performance level & $\begin{array}{r}P A A_{50, \text { min }} \\
{[\mathrm{g}]}\end{array}$ & $\begin{array}{r}P A A_{50, \text { ref }} \\
{[\mathrm{g}]}\end{array}$ & $\begin{array}{r}P A A_{50, \text { max }} \\
{[\mathrm{g}]}\end{array}$ & AR \\
\hline O & 0.25 & 0.26 & 0.28 & 0.11 \\
\hline IO & 0.43 & 0.46 & 0.48 & 0.097 \\
\hline LS & 0.60 & 0.65 & 0.67 & 0.099 \\
\hline CP & 1.29 & 1.55 & 1.55 & 0.16 \\
\hline
\end{tabular}

Table 8: Lower bound, reference value and upper bound of the 90th fractile of the peak absolute acceleration (PAA) in the first numerical example

\begin{tabular}{c|r|r|r|c} 
Performance level & $\begin{array}{r}P A A_{90, \text { min }} \\
{[\mathrm{g}]}\end{array}$ & $\begin{array}{r}P A A_{90, \text { ref }} \\
{[\mathrm{g}]}\end{array}$ & $\begin{array}{r}P A A_{90, \text { max }} \\
{[\mathrm{g}]}\end{array}$ & AR \\
\hline $\mathrm{O}$ & 0.41 & 0.45 & 0.49 & 0.19 \\
\hline IO & 0.88 & 0.99 & 0.99 & 0.12 \\
\hline LS & 1.52 & 1.54 & 1.71 & 0.12 \\
\hline CP & 4.07 & 4.07 & 5.31 & 0.31 \\
\hline
\end{tabular}

interesting to note here how different EPDs for the same structure give rise to MFs with different shapes, and this is something that must be accounted for if one wants to properly quantify the likelihood of structural and nonstructural failures and their consequences (or, better, their degree of belief). For instance, the analysis of Figures 11, 12 and 13 clearly show that, for the structure under consideration, adopting the reference values for the connections' fixity factors leads to progressively less conservative estimates of both PAA and PD when considering seismic events of increasing intensity and higher values of the response fractiles. The MBM, on the contrary, is not affected by this trend.

\subsubsection{Design curves}

Once the MFs of MBM, PAA and PD have been obtained, design curves can be established, as described in Section 5. The defuzzification of the MFs can be achieved, for instance, as a given percentile under their area, e.g. 95\%; that is, for the $Y$ th fractile of the generic EDP at a certain IM level, the 


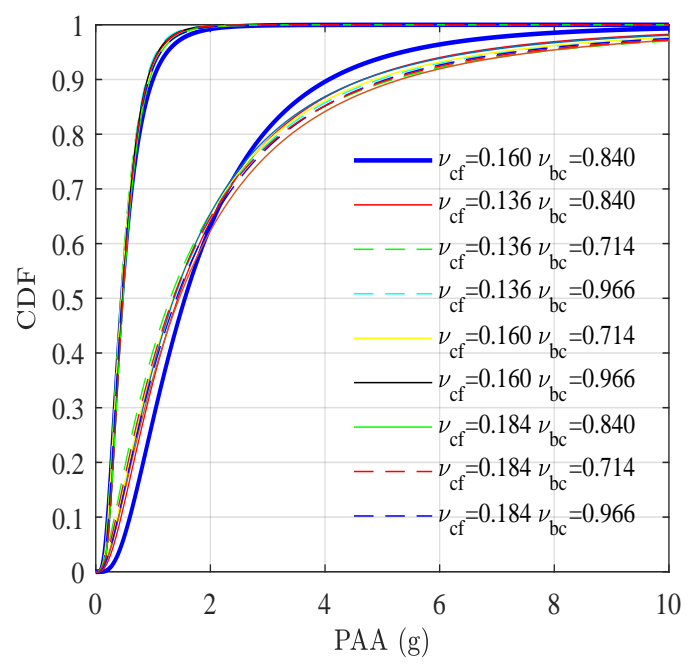

(a)

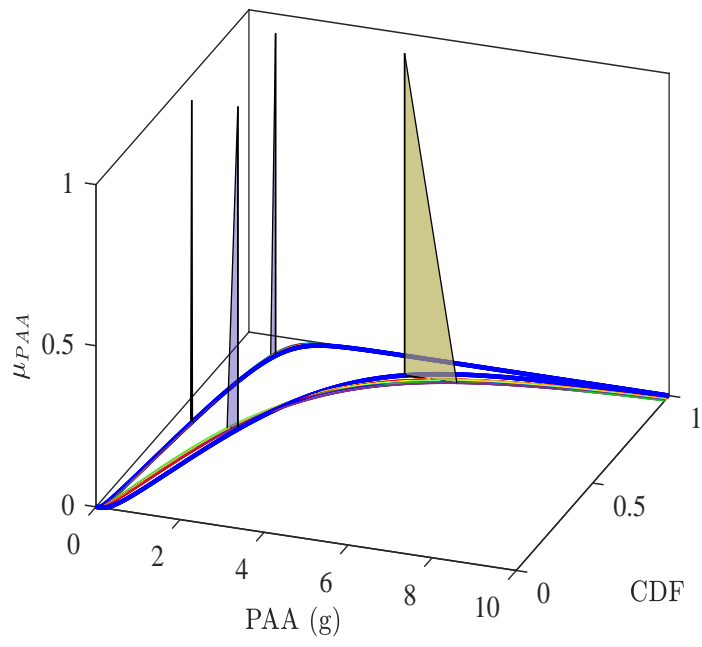

(b)

Figure 12: IO (immediate occupancy) and CP (collapse prevention) performance levels for the peak absolute acceleration (PAA) in the first numerical example: (a) response curves; (b) membership functions of median and 90th percentile

design value $E P D_{Y, \text { des }}(I M)$ satisfies the condition:

$$
\frac{\int_{E D P_{\min }(I M)}^{E P D_{Y, \text { des }}(I M)} \mu_{E P D_{Y}(I M)}(s) \mathrm{d} s}{\int_{E D P_{\min }(I M)}^{E P D_{\max }(I M)} \mu_{E P D_{Y}(I M)}(s) \mathrm{d} s}=0.95,
$$

where $s$ denotes the integration variable used for the MF $\mu_{E P D_{Y}(I M)}$ of the IM-dependent EDP at its $Y$ th fractile.

Figure 14 shows the comparisons between the design curves (thick lines) of MBM, PAA and PD obtained for the performance levels of IO (red) and CP (blue), along with their envelope (shadowed grey areas), which visually demonstrates the effects of the uncertainty associated with the fuzzy fixity factors. Figure 15 depicts the design curves obtained for all the four performance levels considered as part of this numerical application. As expected, the performance level of CP is always characterised by design curves with both higher median and larger dispersion than the design curves of the other three performance levels. 
Table 9: Lower bound, reference value and upper bound of the median of the peak displacement $(\mathrm{PD})$ in the first numerical example

\begin{tabular}{c|r|r|r|c} 
Performance level & $\begin{array}{r}P D_{50, \text { min }} \\
{[\mathrm{m}]}\end{array}$ & $\begin{array}{r}P D_{50, \text { ref }} \\
{[\mathrm{m}]}\end{array}$ & $\begin{array}{c}P D_{50, \text { max }} \\
{[\mathrm{m}]}\end{array}$ & $\mathrm{AR}$ \\
\hline $\mathrm{O}$ & 0.0243 & 0.0245 & 0.0261 & 0.07 \\
\hline $\mathrm{IO}$ & 0.0624 & 0.0631 & 0.0652 & 0.04 \\
\hline $\mathrm{LS}$ & 0.192 & 0.202 & 0.205 & 0.06 \\
\hline $\mathrm{CP}$ & 0.509 & 0.562 & 0.566 & 0.10 \\
\hline
\end{tabular}

Table 10: Lower bound, reference value and upper bound of the 90th fractile of the peak displacement $(\mathrm{PD})$ in the first numerical example

\begin{tabular}{c|r|r|r|c} 
Performance level & $\begin{array}{r}P D_{90, \text { min }} \\
{[\mathrm{m}]}\end{array}$ & $\begin{array}{r}P D_{90, \text { ref }} \\
{[\mathrm{m}]}\end{array}$ & $\begin{array}{r}P D_{90, \text { max }} \\
{[\mathrm{m}]}\end{array}$ & AR \\
\hline $\mathrm{O}$ & 0.0266 & 0.0310 & 0.0318 & 0.17 \\
\hline $\mathrm{IO}$ & 0.118 & 0.129 & 0.132 & 0.11 \\
\hline $\mathrm{LS}$ & 0.457 & 0.479 & 0.514 & 0.12 \\
\hline $\mathrm{CP}$ & 1.47 & 1.47 & 2.16 & 0.47 \\
\hline
\end{tabular}

\subsection{Case study \#2: Pre-assembled modular pipe-rack}

In order to validate the proposed procedure also with a real case-study structure, the seismic performance of a steel pipe-rack adapted from an actual modular steel frame designed for a petrochemical plant has been analysed (the application of the conventional PEER's PBD framework for the same case-study structure can be found in Ref. [79]). The structure consists of a pre-assembled rack (PAR), which is $12 \mathrm{~m}$ long, $8 \mathrm{~m}$ wide and $10 \mathrm{~m}$ tall, and it is used to support process pipes and electrical trays at different level of elevation (EL) (Figure 16(b)). The structure is made of hot-rolled sections of ASTM A572 grade 50 steel, with thick-plate girders, which make the structure quite stiff. ASCE/SEI 7-10 [72] and AISC 360-05 [80] are the main codes that have been used to design it. Link elements have been inserted in each column-to-foundation and beam-to-column joint, with $\nu_{c f}=0.15$ and $\nu_{b c}=0.70$ being the reference values for their respective fixity factors. The latter might correspond to an end-plate connection, with or without column stiffeners [2]. The resulting fundamental period of vibration in the direction 


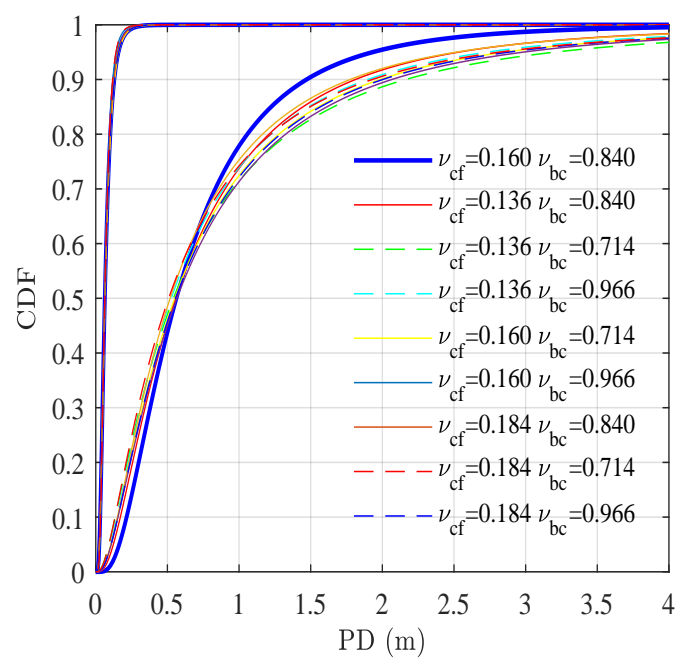

(a)

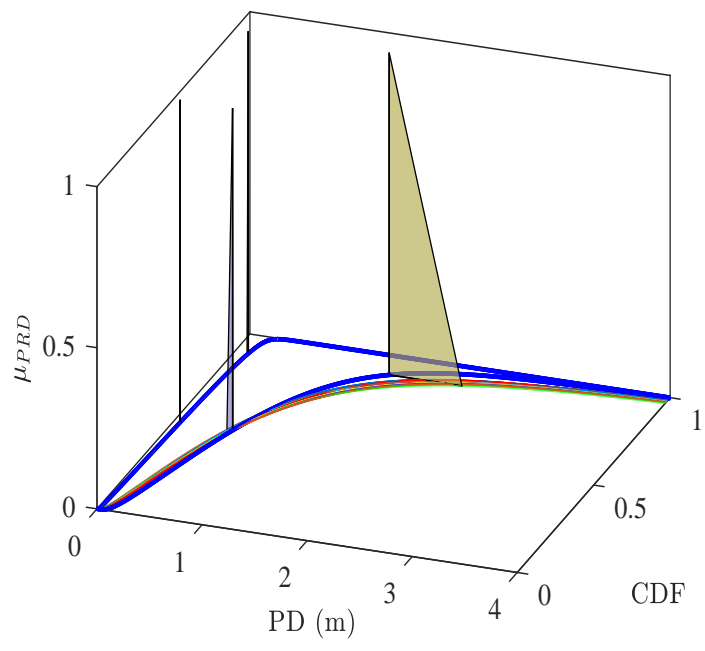

(b)

Figure 13: IO (immediate occupancy) and CP (collapse prevention) performance levels for the peak displacement (PD) in the first numerical example: (a) response curves; (b) membership functions of median and 90th percentile

being analysed is $T_{1, r e f}=0.22 \mathrm{~s}$.

Similar to the case of the first numerical example, triangular MFs have been assumed for the fuzzy fixity factors, considering bounds of $\pm 15 \%$ with respect to the reference values. As shown in Figure 17(a) and (b), three $\alpha$-cuts have been considered in this case, namely $\alpha=0, \alpha=0.5$ and $\alpha=1$. Thus, $n_{S T R}=17$ combinations of the $n_{d}=2$ fuzzy variables have been analysed (see Fig. 17(c)), which are listed in Table 11 along with the corresponding values of $T_{1}$. Figure 18 shows the resulting MF, whose AR of 0.12 is $60 \%$ less than the AR of the fixity factors. Also in this case, thus, the choice of $I M=S_{a}\left(T_{1, r e f}\right)$ appears justified.

The same analyses as for the first numerical example have been carried out for the industrial modular structure. In a first stage, the hazard curve of Figure 19 has been obtained, assuming the same location, and the values of the spectral acceleration for a PoE in 50 years of $5,10, \cdots, 95 \%$ are listed in Table 12. Due to the a lower value of $T_{1, r e f}$, the spectral accelerations of the pipe rack are higher than in the case of the first numerical example (see 


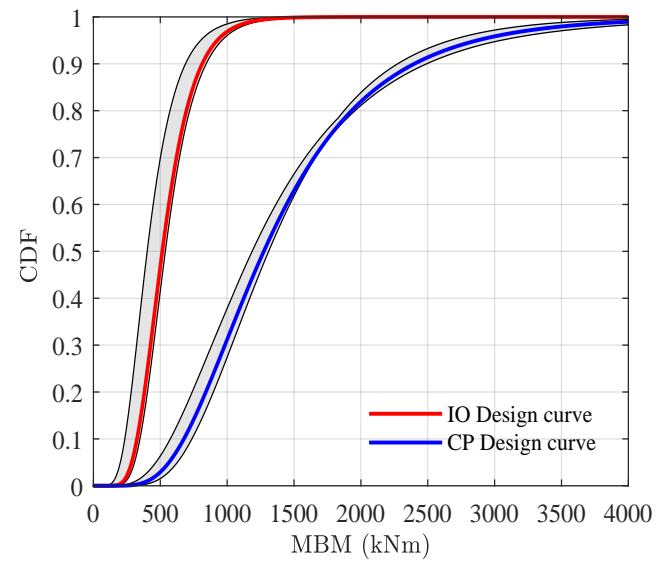

(a)

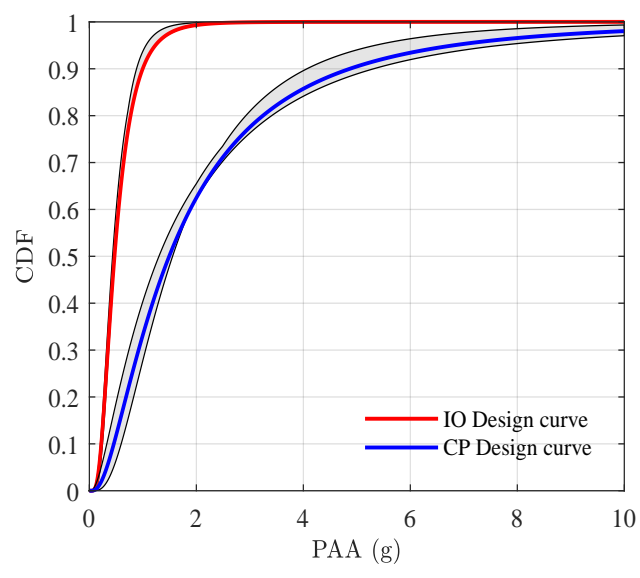

(b)

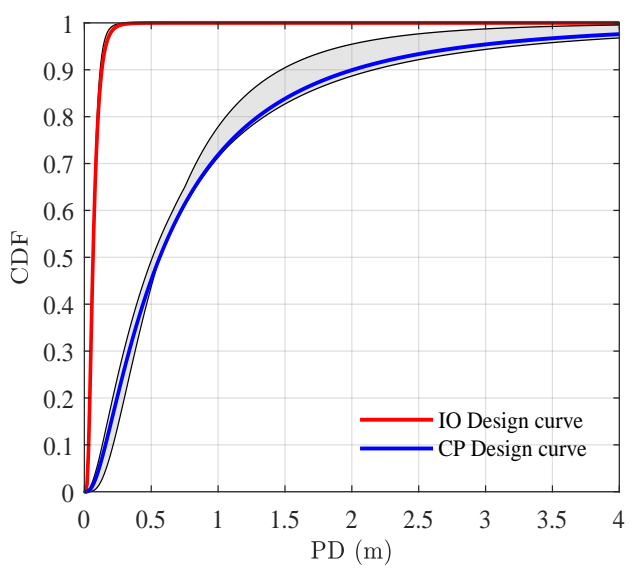

(c)

Figure 14: Design curves for the IO (immediate occupancy) and CP (collapse prevention) performance levels in the first numerical example: (a) maximum bending moment (MBM); (b) peak absolute acceleration (PAA); (c) peak displacement (PD) 


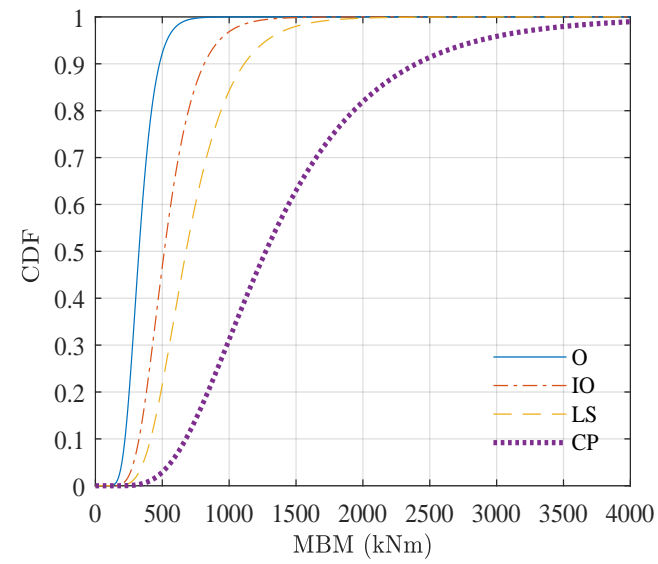

(a)

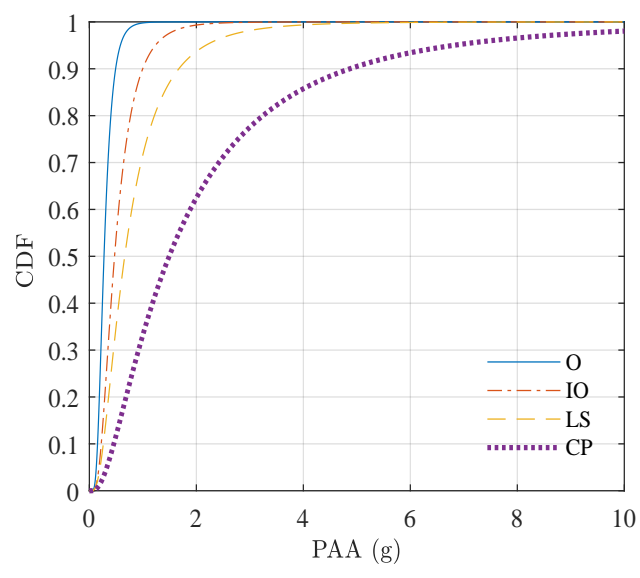

(b)

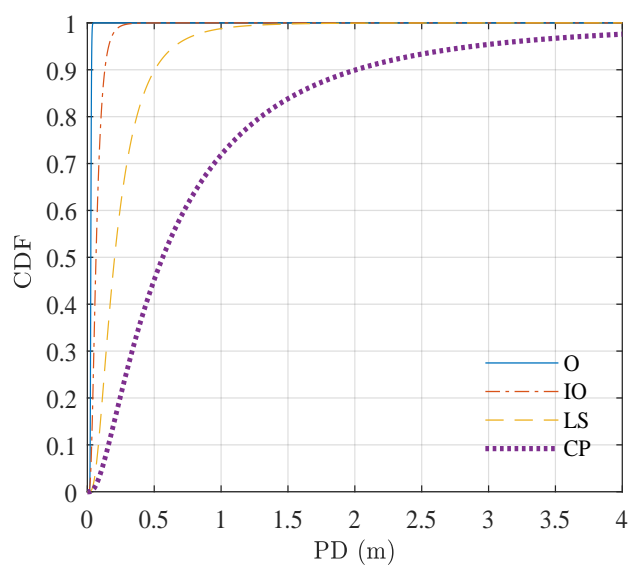

(c)

Figure 15: Design curves for the four performance levels in the first numerical example: (a) maximum bending moment (MBM); (b) peak absolute acceleration (PAA) (c) peak displacement $(\mathrm{PD})$ 


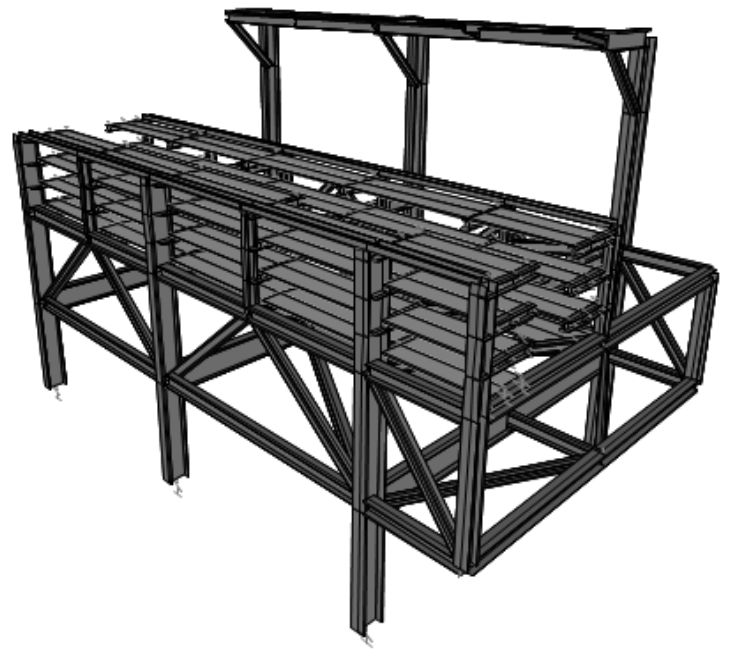

(a)

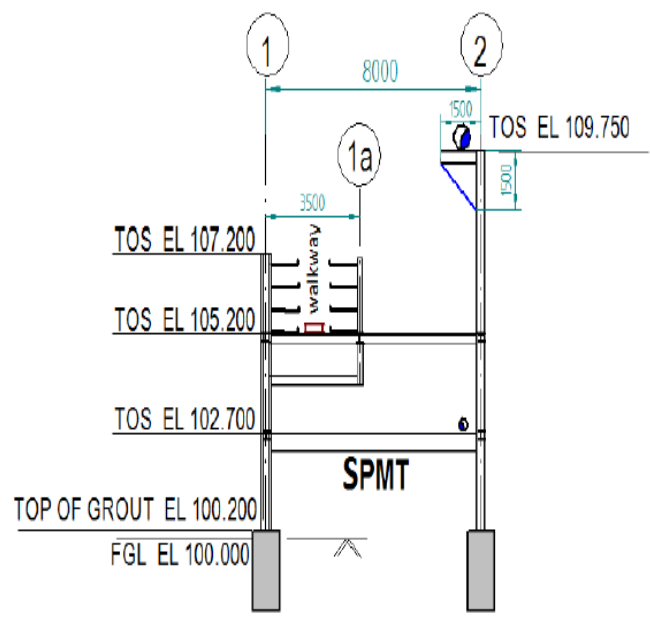

(b)

Figure 16: Industrial modular structures used as second numerical example: (a) 3D view; (b) elevation

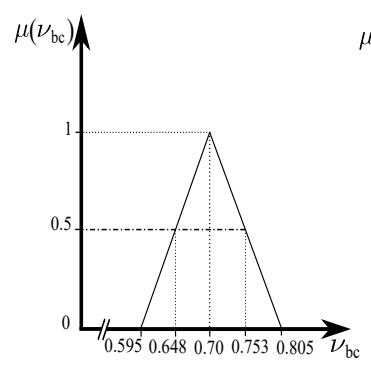

(a)

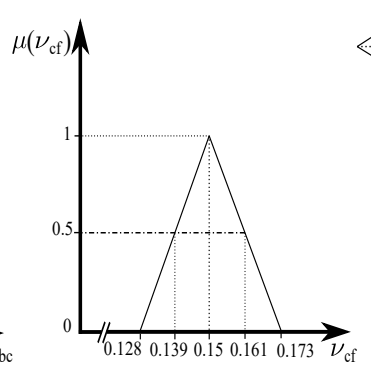

(b)

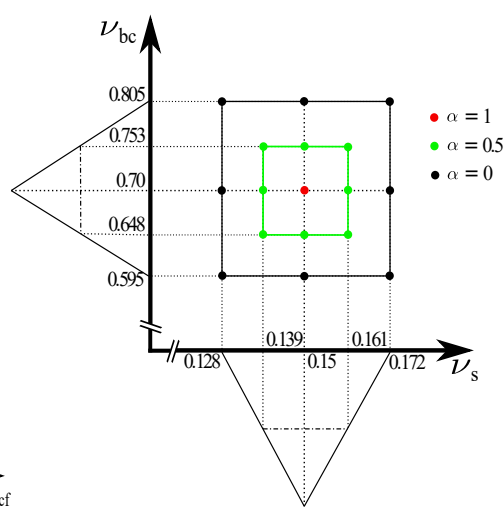

(c)

Figure 17: Membership functions for the second numerical example: (a) beam-to-column connections; (b) column-to-foundations connections; (c) top view of the pyramidal function 
Table 11: Combinations of the fixity factors in the second numerical example

\begin{tabular}{c|r|r|r} 
Combination $\#$ & $\nu_{c f}$ & $\nu_{b c}$ & $T_{1}[\mathrm{~s}]$ \\
\hline 1 & 0.15 & 0.70 & 0.222 \\
\hline 2 & 0.1275 & 0.70 & 0.225 \\
\hline 3 & 0.1275 & 0.5950 & 0.237 \\
\hline 4 & 0.1275 & 0.8050 & 0.214 \\
\hline 5 & 0.15 & 0.5950 & 0.234 \\
\hline 6 & 0.15 & 0.8050 & 0.212 \\
\hline 7 & 0.1725 & 0.70 & 0.219 \\
\hline 8 & 0.1725 & 0.5950 & 0.231 \\
\hline 9 & 0.1725 & 0.8050 & 0.210 \\
\hline 10 & 0.1387 & 0.70 & 0.227 \\
\hline 11 & 0.1387 & 0.6475 & 0.217 \\
\hline 12 & 0.1387 & 0.7525 & 0.223 \\
\hline 13 & 0.15 & 0.6475 & 0.221 \\
\hline 14 & 0.15 & 0.7525 & 0.229 \\
\hline 15 & 0.1613 & 0.70 & 0.218 \\
\hline 16 & 0.1613 & 0.6475 & 0.226 \\
\hline 17 & 0.1613 & 0.7525 & 0.216 \\
\hline & & &
\end{tabular}

Table 3).

In a second stage, two EDPs have been considered, namely the maximum bending moment (MBM) of the first floor beams and the peak absolute accelerations (PAA) of a single-degree-of-freedom (SDoF) oscillator of period $T_{1, \text { ref }}$ attached to the free end of the cantilever beams supporting the pipes. For each IM level of the seismic hazard, and for every combination of the fuzzy variables at each $\alpha$-cut level of the input MFs, each EDP has been characterised probabilistically in terms of its CCDF, that is $F[E D P \mid I M]$, obtained by best-fitting a lognormal model with the results of the seismic analyses (in total, $n_{I M} \times n_{S T R} \times n_{E Q}=10 \times 17 \times 7=1,190$ nonlinear time-history analyses have been carried out).

In a third stage, for each EDP and each structural model combination, the least square method has been used to find the optimal regression curves 


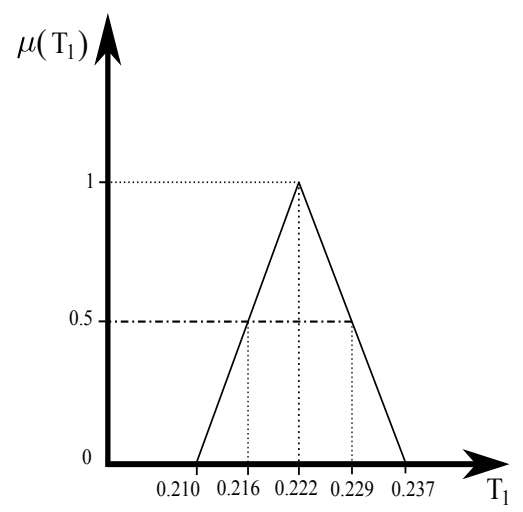

Figure 18: Membership function of the fundamental period $T_{1}$ for the second numerical example

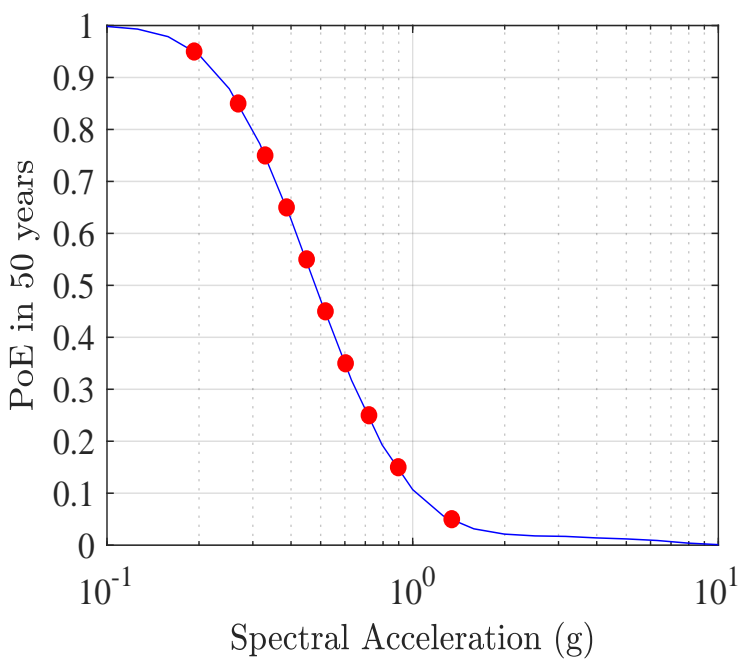

Figure 19: Hazard curve of the second numerical example 
Table 12: IM levels for the hazard curve of the second numerical example

\begin{tabular}{c|r} 
IM level & $S_{a}\left(T_{1_{r} e f}\right)[\mathrm{g}]$ \\
\hline I & 0.192 \\
\hline II & 0.268 \\
\hline III & 0.329 \\
\hline IV & 0.386 \\
\hline V & 0.449 \\
\hline VI & 0.518 \\
\hline VII & 0.603 \\
\hline VIII & 0.719 \\
\hline IX & 0.897 \\
\hline X & 1.34 \\
\hline
\end{tabular}

Table 13: Probability of exceedance in 50 years for the four performance levels considered in the structural analysis, and corresponding spectral accelerations in the hazard curve for the second numerical example

\begin{tabular}{c|r|r} 
Performance level & $P_{o} E_{50}[\%]$ & $S_{a}\left(T_{1, r e f}\right)[\mathrm{g}]$ \\
\hline $\mathrm{O}$ & 50 & 0.48 \\
\hline IO & 20 & 0.78 \\
\hline LS & 10 & 1.05 \\
\hline CP & 2.0 & 2.19 \\
\hline
\end{tabular}

which approximate the variation with the IM of the position and dispersion parameters of the lognormal model, allowing then to define the lognormal distributions for the pre-defined performance levels (namely, O, IO, LS and $\mathrm{CP})$. For illustration purposes, the $n_{S T R}=17 \mathrm{CCDFs}$ of MBM and PAA for immediate occupancy (IO, subplots (a)) and collapse preventions (CP, subplots (c)) are displayed in Figures 20 and 21, respectively, along with a $3 \mathrm{D}$ visualisation of the MFs of the median and 90th fractile (subplots (b) and (d)). Contrary to what has been observed with the first numerical example, the effects of the fuzziness in the steel connections affects the MBM more than the PAA.

Finally, the design curves for both MBM and PAA have been obtained, considering the $95 \%$ percentile of the area under their MFs. The design 


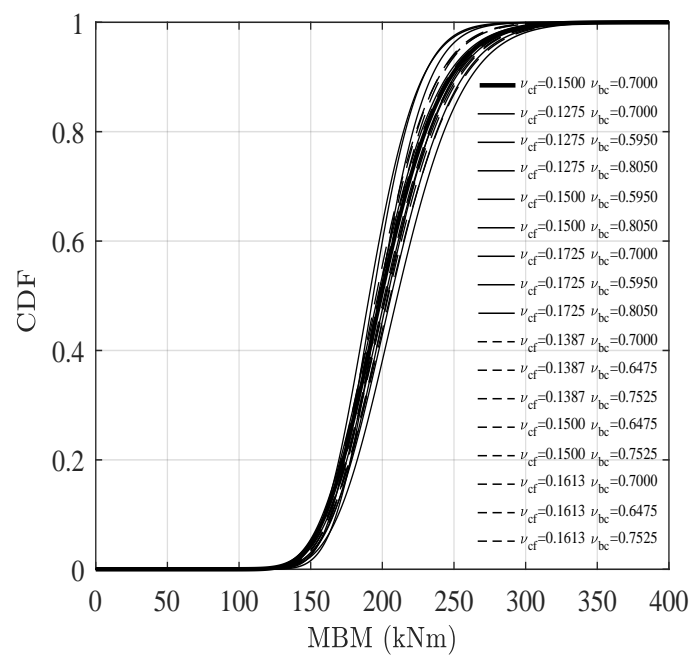

(a)

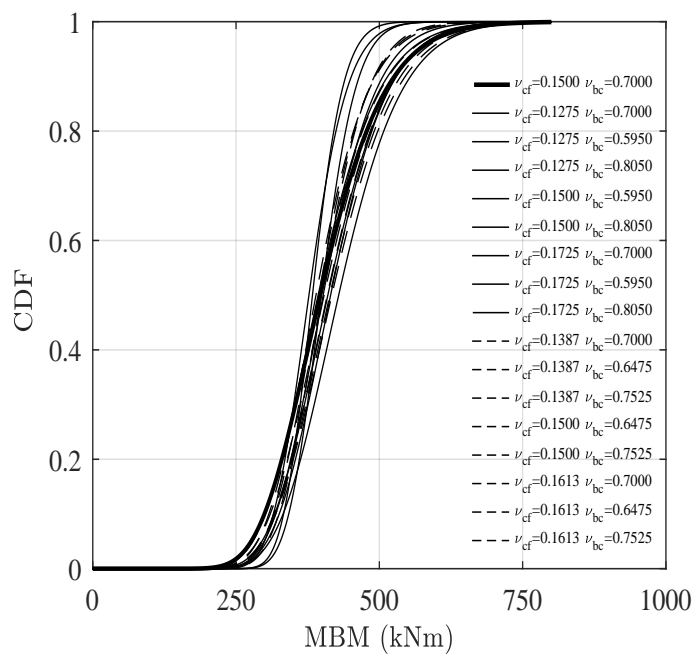

(c)

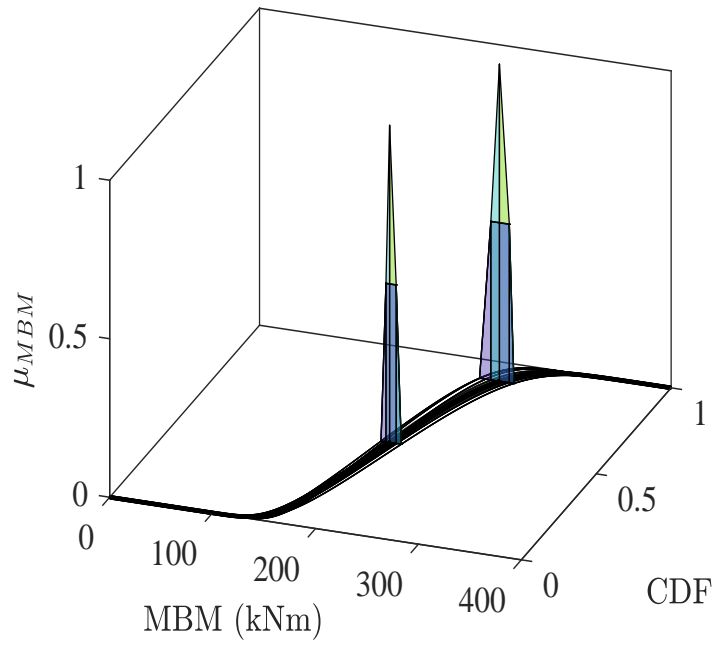

(b)

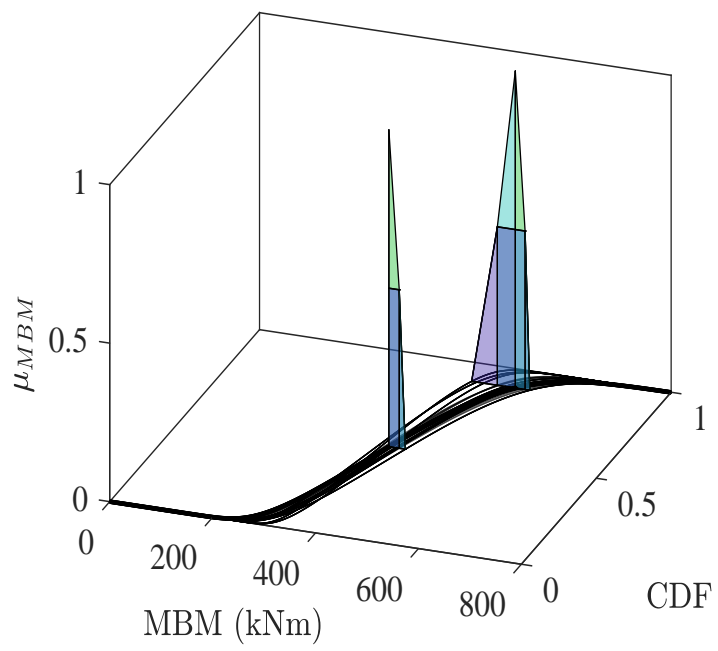

(d)

Figure 20: IO (top plots) and CP (bottom plots) performance levels for the maximum bending moment (MBM) in the second numerical example: response curves (left plots) and membership functions (right plots) of median and 90th percentile 


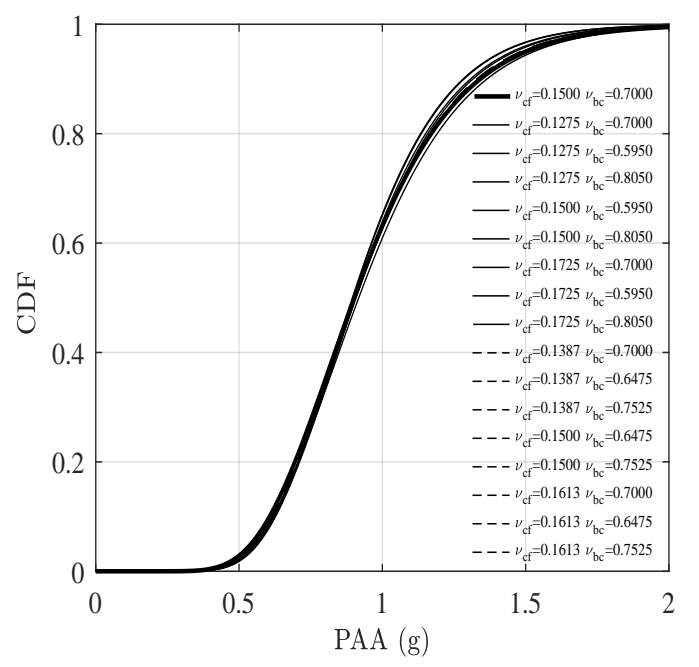

(a)

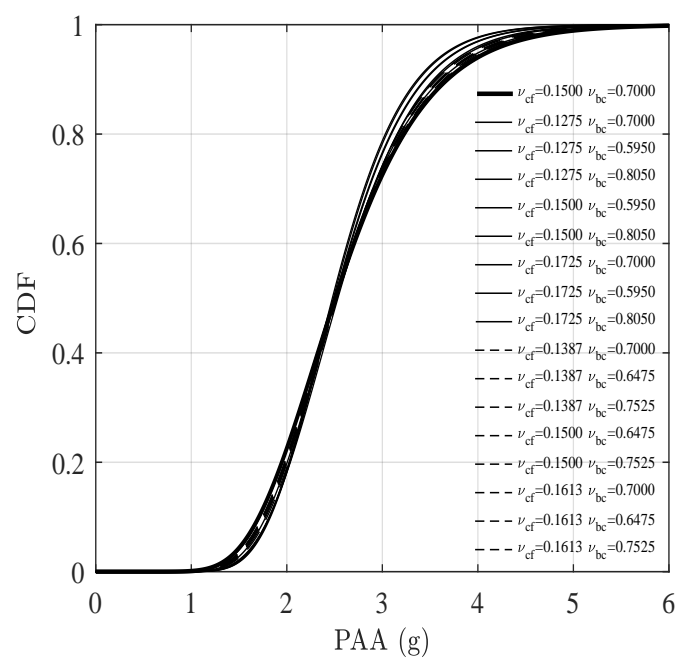

(c)

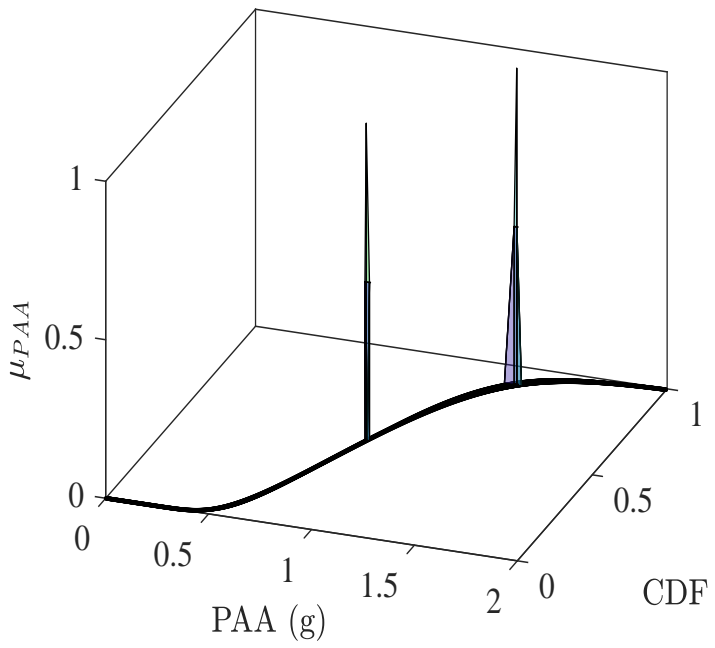

(b)

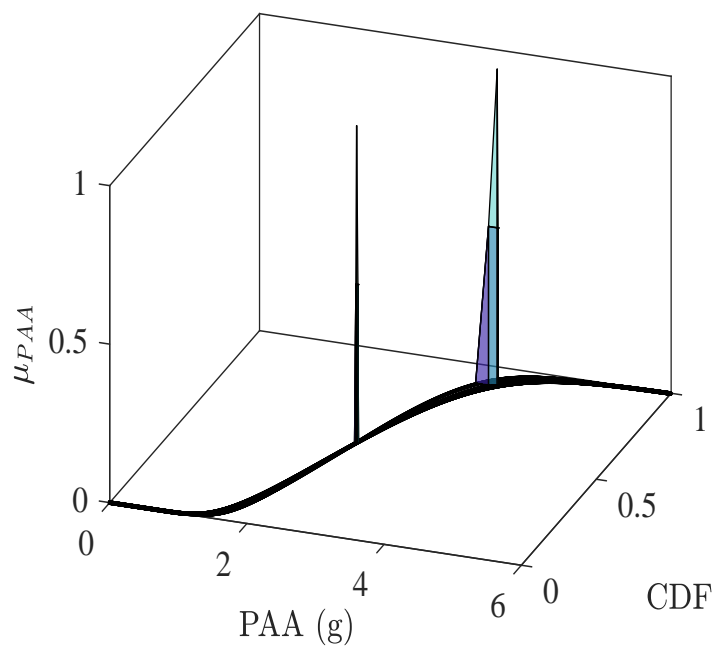

(d)

Figure 21: IO (top plots) and CP (bottom plots) performance levels for the peak absolute acceleration (PAA) in the second numerical example: response curves (left plots) and membership functions (right plots) of median and 90th percentile 


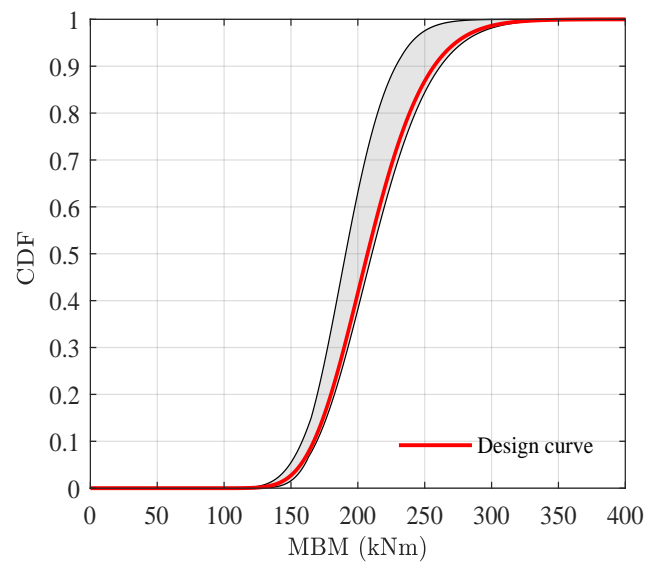

(a)

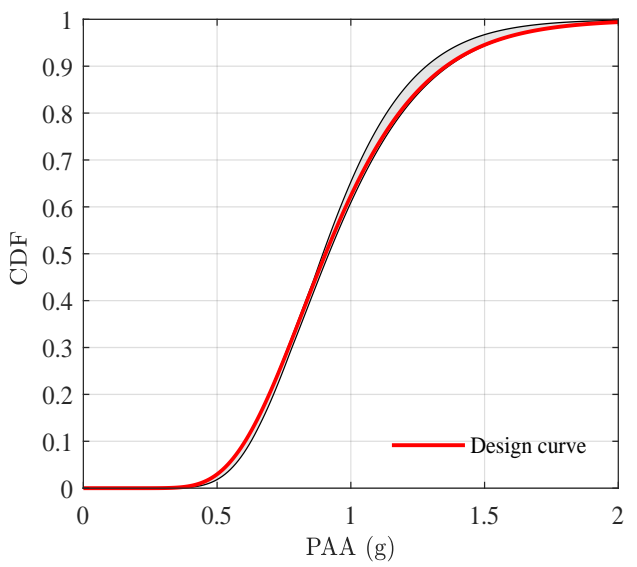

(b)

Figure 22: Design curves for the IO (immediate occupancy) performance level in the second numerical example: (a) MBM; (b) PAA

curves at the IO and CP performance levels are shown in Figures 22 and 23, respectively, where the shadowed grey areas visualise the envelopes of the CCDF, confirming that for this numerical application the uncertainty in the fixity factors of the connections affects more the MBM than the PAA.

\section{Conclusions}

In this paper, a new performance-based fuzzy design (PBFD) procedure has been presented for steel moment-resisting frames, considering the effects of different sources of uncertainty, namely aleatory randomness on the seismic demand and epistemic uncertainty on the semi-rigidity of both column-to foundation and beam-to-column connections. In particular, the non-deterministic behaviour of the connections has been modelled by means of fuzzy variables with a triangular membership function (MF) for their fixity factors. The proposed framework is an extended version of the classical PEER's performance-based design (PBD) approach, in which an additional stage has been introduced as part of the structural analysis, namely the fuzzy analysis, which allows characterising the MF of the engineering demand parameters (EDPs) of interest. 


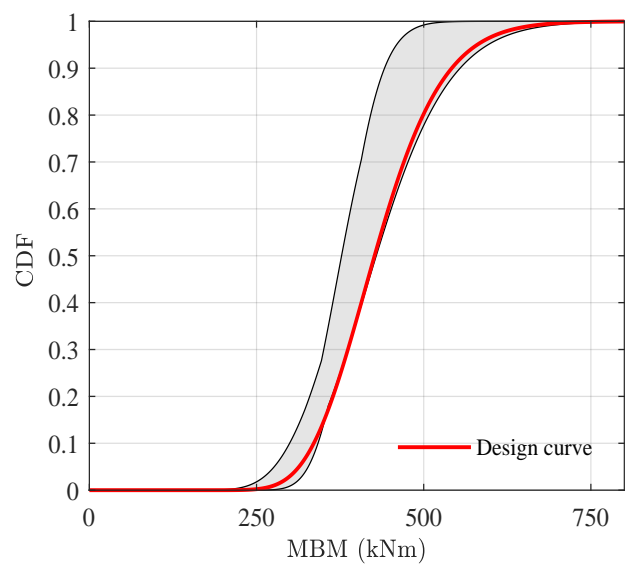

(a)

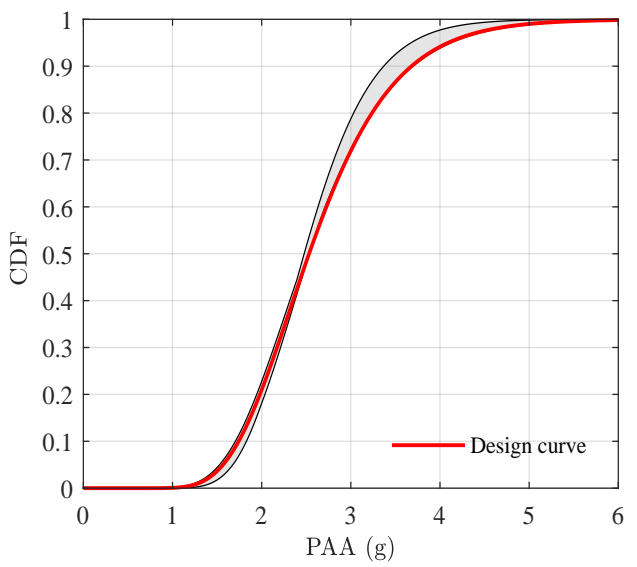

(b)

Figure 23: Design curves for the CP (collapse prevention) performance level in the second numerical example: (a) MBM; (b) PAA

The proposed approach has been applied to a planar steel frame and to an industrial 3D modular structure, exploiting a commercial structural analysis programme (SAP2000) within a general numerical computing environment (MATLAB). The results demonstrate that the proposed PBFD procedure provides a deeper insight into the expected seismic performance of the structures being analysed, particularly if the effects of epistemic uncertainties are significant. This is indeed the case for industrial steel structures, in which the actual flexibility of the connections is very often overlooked, and in fact their detailing is routinely left to the steel fabricators. As the structural engineering team responsible for the main structural design of the steel frame typically has little or no information about the connections details that will be specified and realised by the fabricators, the adoption of fuzzy variables for the stiffness of the connections appears particularly appropriate.

Interestingly, it has been shown that using the reference values for the fixity factors of the steel connections deterministically, i.e. those for which the triangular MF is assumed to be equal to 1, can either under- or over-estimate the majority of the results obtained by varying the values of the fuzzy design variables within their domains of definition (i.e. zero $\alpha$-cuts). Potentially, this has huge consequences in terms of risk and resilience assessment, that can be properly quantified with the proposed formulation. 
It should also be noted that, since fuzzy structural analysis can be easily task-parallelised, a significant advantage exists in that the probabilistic characterisation of the EDPs, potentially cumbersome from a computational point of view, can be achieved concurrently for the various combinations of the fuzzy model parameters. This significantly reduces the overall time for the completion of the analyses.

Based on the available results, further research will be required on various aspects of the procedure, particularly the optimal number of earthquake records for each level of the seismic intensity measure (IM), the optimal number of $\alpha$-cuts for the fuzzy design variables and the defuzzification method to extract the design values from the MFs of the EDPs.

Although the focus in this paper has been on seismic hazard and stiffness of the connection, the proposed fuzzified PBD framework can be applied to different sources of hazards, including multi-hazard scenarios, and to different design parameters, e.g. the strength and ductility of the connections, the properties of the foundation soil, etcetera.

\section{Appendix A. Notation}

In this paper, the following key symbols and acronyms have been used:

List of symbols

$$
\begin{aligned}
D M & =\text { Damage measure; } \\
D V & =\text { Decision variable; } \\
E & =\text { Young's modulus; } \\
E D P_{i, Y} & =Y \text { th fractile of the } i \text { th engineering demand parameter; } \\
F[\cdot] & =\text { Cumulative distribution function; } \\
I & =\text { Second moment of area; } \\
k_{c} & =\text { Rotational stiffness of the semi-rigid connection; } \\
l & =\text { Length of the steel member; } \\
I M_{h} & =h \text { th value of the intensity measure for the seismic hazard; } \\
M & =\text { Bending moment; } \\
n_{d} & =\text { Number of fuzzy design variables; }
\end{aligned}
$$



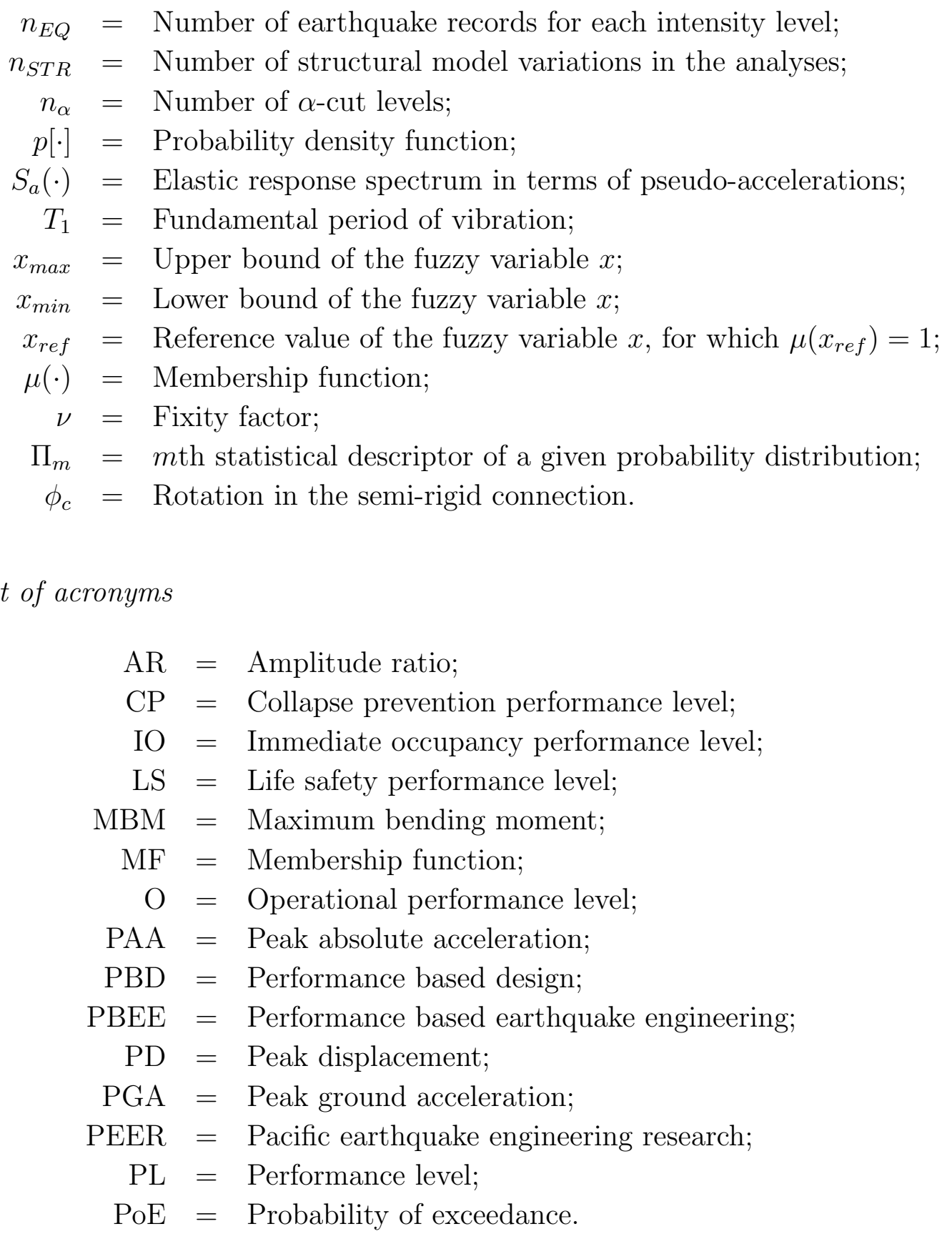


\section{References}

[1] J. Davison, P. Kirby, D. Nethercot, Rotational stiffness characteristics of steel beam-to-column connections, Journal of Constructional Steel Research 8 (1987) 17-54.

[2] W.-F. Chen, Semi-Rigid Connections Handbook, J. Ross Publishing, 2011.

[3] M. Hadianfard, R. Razani, Effects of semi-rigid behavior of connections in the reliability of steel frames, Structural Safety 25 (2) (2003) 123-138.

[4] K. M. Romstad, C. V. Subramanian, Analysis of frames with partial connection rigidity, ASCE Journal of the Structural Division 96 (11) (1970) 2283-2300.

[5] M. Barakat, W.-F. Chen, Practical analysis of semi-rigid frames, Engineering Journal 27 (2) (1990) 54-68.

[6] S. Kawashima, T. Fujimoto, Vibration analysis of frames with semi-rigid connections, Computers \& Structures 19 (1-2) (1984) 85-92.

[7] N. Kishi, W.-F. Chen, Moment-rotation relations of semirigid connections with angles, Journal of Structural Engineering 116 (7) (1990) 18131834.

[8] P. D. Moncarz, K. H. Gerstl, Steel frames with nonlinear connections, ASCE Journal of the Structural Division 107 (8) (1981) 1427-1441.

[9] M. Ivanyi, C. C. Baniotopoulos, Eds., Semi-Rigid Joints in Structural Steelwork, Springer, 2000.

[10] M. Sekulovic, R. Salatic, M. Nefovska, Dynamic analysis of steel frames with flexible connections, Computers \& Structures 80 (11) (2002) 935955.

[11] E. Bayo, J. Cabrero, B. Gil, An effective component-based method to model semi-rigid connections for the global analysis of steel and composite structures, Engineering Structures 28 (1) (2006) 97-108. 
[12] J. Cabrero, E. Bayo, Development of practical design methods for steel structures with semi-rigid connections, Engineering Structures 27 (8) (2005) 1125-1137.

[13] H. Kobayashi, B. L. Mark, W. Turin, Probability, Random Processes, and Statistical Analysis, Cambridge University Press, 2011.

[14] L. A. Zadeh, Fuzzy sets, Information and Control 8 (3) (1965) 338-353.

[15] G. Klir, B. Yuan, Fuzzy sets and fuzzy logic, Vol. 4, Prentice Hall New Jersey, 1995.

[16] H. Kwakernaak, Fuzzy random variables. Definitions and theorems, Information Sciences 15 (1) (1978) 1-29.

[17] M. L. Puri, D. A. Ralescu, Fuzzy random variables, Journal of Mathematical Analysis and Applications 114 (2) (1986) 409-422.

[18] G. Wang, Y. Zhang, The theory of fuzzy stochastic processes, Fuzzy Sets and Systems 51 (2) (1992) 161-178.

[19] N. D. Lagaros, Fuzzy fragility analysis of structures with masonry infill walls, Open Construction and Building Technology Journal 6 (2012) 291-305.

[20] F. Colangelo, A simple model to include fuzziness in the seismic fragility curve and relevant effect compared with randomness, Earthquake Engineering \& Structural Dynamics 41 (5) (2012) 969-986.

[21] F. Colangelo, Probabilistic characterisation of an analytical fuzzyrandom model for seismic fragility computation, Structural Safety 40 (2013) 68-77.

[22] J.-R. Huo, H. H. Hwang, Incorporation of fuzzy damage states in seismic fragility analysis, in: Probabilistic Mechanics \& Structural Reliability, ASCE, 1996, pp. 318-321.

[23] A. Der Kiureghian, O. Ditlevsen, Aleatory or epistemic? Does it matter?, Structural Safety 31 (2) (2009) 105-112. 
[24] J. Song, B. R. Ellingwood, Seismic reliability of special moment steel frames with welded connections: I, Journal of Structural Engineering 125 (4) (1999) 357-371.

[25] J. Song, B. R. Ellingwood, Seismic reliability of special moment steel frames with welded connections: II, Journal of Structural Engineering 125 (4) (1999) 372-384.

[26] O.-S. Kwon, A. Elnashai, The effect of material and ground motion uncertainty on the seismic vulnerability curves of RC structure, Engineering Structures 28 (2) (2006) 289-303.

[27] A. Kazantzi, D. Vamvatsikos, D. Lignos, Seismic performance of a steel moment-resisting frame subject to strength and ductility uncertainty, Engineering Structures 78 (2014) 69-77.

[28] S. Kasinos, Seismic Response Analysis of Linear and Nonlinear Secondary Structures, Ph.D. thesis, Loughborough University (2018).

[29] M. Mancini, Ed., Advances in plant modularisation: From the state of art to emerging challenges, ANIMP Servizi SRL, 2014.

[30] A. Ghobarah, Performance-based design in earthquake engineering: state of development, Engineering Structures 23 (8) (2001) 878-884.

[31] M. Tang, E. Castro, F. Pedroni, A. Brzozowski, M. Ettouney, Performance-based design with application to seismic hazard, Structure Magazine 15 (6) (2008) 20-22.

[32] K. A. Porter, An overview of PEER's performance-based earthquake engineering methodology, in: 9th International Conference on Applications of Statistics and Probability in Civil Engineering, 2003.

[33] T.-H. Lee, K. M. Mosalam, Probabilistic seismic evaluation of reinforced concrete structural components and systems, Tech. Rep. PEER 2006/04, Pacific Earthquake Engineering Research Center (2006).

[34] H. Krawinkler, S. Mohasseb, Effects of panel zone deformations on seismic response, Journal of Constructional Steel Research 8 (C) (1987) $233-250$. 
[35] S. P. Schneider, A. Amidi, Seismic behavior of steel frames with deformable panel zones, Journal of Structural Engineering 124 (1) (1998) $35-42$.

[36] C. Mao, J. Ricles, L.-W. Lu, J. Fisher, Seismic behavior of steel frames with deformable panel zones, Journal of Structural Engineering 127 (9) (2001) 1036-1044.

[37] C. Díaz, P. Martí, M. Victoria, O. M. Querin, Review on the modelling of joint behaviour in steel frames, Journal of Constructional Steel Research 67 (5) (2011) 741-758.

[38] Y. L. Yee, R. E. Melchers, Moment-rotation curves for bolted connections, Journal of Structural Engineering 112 (3) (1986) 615-635.

[39] R. P. Johnson, C. Law, Semi-rigid joints for composite frames, in: International Conference on Joints in Structural Steelwork, Pentech Press, London, 1981, pp. 3-3.

[40] M. J. Frye, G. A. Morris, Analysis of flexibly connected steel frames, Canadian Journal of Civil Engineering 2 (3) (1975) 280-291.

[41] N. Krishnamurthy, Analytical investigation of bolted stiffened tee stubs, in: Report No. CE-MBMA-1902, Department of Civil Engineering, Vanderbilt University Nashville, Tennessee, USA, 1978.

[42] A. Kukreti, T. Murray, A. Abolmaali, End-plate connection momentrotation relationship, Journal of Constructional Steel Research 8 (1987) 137-157.

[43] E. P. Popov, S. M. Takhirov, Bolted large seismic steel beam-to-column connections part 1: experimental study, Engineering Structures 24 (12) (2002) 1523-1534.

[44] A. M. G. Coelho, F. S. Bijlaard, L. S. da Silva, Experimental assessment of the ductility of extended end plate connections, Engineering Structures 26 (9) (2004) 1185-1206.

[45] A. M. G. Coelho, F. S. Bijlaard, N. Gresnigt, L. S. da Silva, Experimental assessment of the behaviour of bolted t-stub connections made up of welded plates, Journal of Constructional Steel research 60 (2) (2004) 269-311. 
[46] C. Faella, V. Piluso, G. Rizzano, Structural steel semirigid connections: theory, design, and software, Vol. 21, CRC Press, 1999.

[47] X. Dai, Y. Wang, C. Bailey, Numerical modelling of structural fire behaviour of restrained steel beam-column assemblies using typical joint types, Engineering Structures 32 (8) (2010) 2337-2351.

[48] M. E. Lemonis, C. J. Gantes, Mechanical modeling of the nonlinear response of beam-to-column joints, Journal of Constructional Steel Research 65 (4) (2009) 879-890.

[49] M. Mohamadi-Shooreh, M. Mofid, Parametric analyses on the initial stiffness of flush end-plate splice connections using fem, Journal of Constructional Steel Research 64 (10) (2008) 1129-1141.

[50] M. N. Jadid, D. R. Fairbairn, Neural-network applications in predicting moment-curvature parameters from experimental data, Engineering Applications of Artificial Intelligence 9 (3) (1996) 309-319.

[51] A. Cevik, Genetic programming based formulation of rotation capacity of wide flange beams, Journal of Constructional Steel Research 63 (7) (2007) 884-893.

[52] E. Salajegheh, S. Gholizadeh, A. Pirmoz, Self-organizing parallel back propagation neural networks for predicting the moment-rotation behavior of bolted connections, Asian Journal of Civil Engineering 9 (6) (2008) 625-640.

[53] F. G. Al-Bermani, S. Kitipornchai, Elastoplastic nonlinear analysis of flexibly jointed space frames, Journal of Structural Engineering 118 (1) (1992) 108-127.

[54] S. Kasinos, A. Palmeri, S. Maheshwari, M. Lombardo, Dynamic analysis of steel frames with uncertain semi-rigid connections, in: 12th International Conference on Structural Safety \& Reliability, Vienna, Austria, 2017.

[55] F. Biondini, F. Bontempi, P. G. Malerba, Fuzzy reliability analysis of concrete structures, Computers \& Structures 82 (13) (2004) 1033-1052. 
[56] Z. Kala, Stability problems of steel structures in the presence of stochastic and fuzzy uncertainty, Thin-Walled Structures 45 (10) (2007) 861865.

[57] G. C. Marano, G. Quaranta, Fuzzy-based robust structural optimization, International Journal of Solids and Structures 45 (11) (2008) 35443557.

[58] G. C. Marano, G. Quaranta, M. Mezzina, Fuzzy time-dependent reliability analysis of RC beams subject to pitting corrosion, Journal of Materials in Civil Engineering 20 (9) (2008) 578-587.

[59] B. Kosko, Fuzziness vs. probability, International Journal of General System 17 (2-3) (1990) 211-240.

[60] D. Dubois, H. M. Prade, Fuzzy Sets and Systems: Theory and Applications (Mathematics in Science \& Engineering), Vol. 144, Academic Press, 1980.

[61] H. Li, V. C. Yen, Fuzzy Sets and Fuzzy Decision-Making, CRC Press, 1995.

[62] W. Dong, H. C. Shah, Vertex method for computing functions of fuzzy variables, Fuzzy Sets and Systems 24 (1) (1987) 65-78.

[63] SAP2000, version 17.3.0, Computers and Structures Inc., Berkeley, California, 2010.

[64] MATLAB, release R2017a, The MathWorks Inc., Natick, Massachusetts, 2010.

[65] M. Beer, S. Ferson, V. Kreinovich, Imprecise probabilities in engineering analyses, Mechanical Systems and Signal Processing 37 (1-2) (2013) 429 .

[66] SEAOC, SEAOC Vision 2000 Committee. Performance-based seismic engineering, in: 13th World Conference on Earthquake Engineering, 1995.

[67] C. J. Wills, M. Petersen, W. A. Bryant, M. Reichle, G. J. Saucedo, S. Tan, G. Taylor, J. Treiman, A site-conditions map for California 
based on geology and shear-wave velocity, Bulletin of the Seismological Society of America 90 (6B) (2000) S187-S208.

[68] N. Shome, C. Cornell, Probabilistic Seismic Demand Analysis of Nonlinear Structures, Tech. Rep. RMS-35, Stanford University (1993).

[69] E. H. Field, T. H. Jordan, C. A. Cornell, OpenSHA: A developing community-modeling environment for seismic hazard analysis, Seismological Research Letters 74 (4) (2003) 406-419.

[70] T. D. Ancheta, R. B. Darragh, J. P. Stewart, E. Seyhan, W. J. Silva, B. S.-J. Chiou, K. E. Wooddell, R. W. Graves, A. R. Kottke, D. M. Boore, T. Kishida, J. L. Donahue, NGA-West2 database, Earthquake Spectra 30 (3) (2014) 989-1005.

[71] EN 1998-1:2004 - Eurocode 8: Design of Structures for Earthquake Resistance - Part 1: General Rules, Seismic Actions and Rules for Buildings, Standard, European Committee for Standardization (CEN), Brussels, Belgium (2004).

[72] ASCE/SEI 7-10, Minimum Design Loads for buildings and Other Structures, Standard, ASCE, Reston, Virginia (2000).

[73] IBC 2012, Standard, International Code Council (ICC), Falls Church, Virginia (2012).

[74] P. Cacciola, P. Colajanni, G. Muscolino, Combination of modal responses consistent with seismic input representation, Journal of Structural Engineering 130 (1) (2004) 47-55.

[75] I. Iervolino, G. Maddaloni, E. Cosenza, Eurocode 8 compliant real record sets for seismic analysis of structures, Journal of Earthquake Engineering 12 (1) (2008) 54-90.

[76] D. Cecini, A. Palmeri, Spectrum-compatible accelerograms with harmonic wavelets, Computers \& Structures 147 (2015) 26-35.

[77] G. Barone, F. L. Iacono, G. Navarra, A. Palmeri, A novel analytical model of power spectral density function coherent with earthquake response spectra, in: First ECCOMAS Thematic Conference on Uncertainty Quantification in Computational Sciences and Engineering, 2015. 
794

795

796

797

798

799

800

801

[78] E. I. Katsanos, A. G. Sextos, Reliable selection of earthquake ground motions for performance-based design, in: First International Conference on Natural Hazards \& Infrastructure, 2016.

[79] A. de Luca di Roseto, A. Palmeri, A. G. Gibb, Performance-based seismic design of a modular pipe-rack, Procedia Engineering 199 (2017) 3564-3569.

[80] AISC 360-05, Specification for Structural Steel Buildings, Standard, AISC, Chicago, Illinois (2005). 